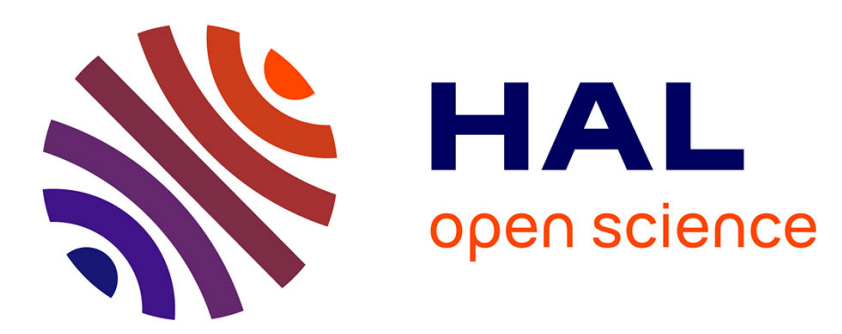

\title{
A new method for extracting knowledge from patents to inspire designers during the problem-solving phase
}

Ulises Valverde, Jean-Pierre Nadeau, Dominique Scaravetti

\section{To cite this version:}

Ulises Valverde, Jean-Pierre Nadeau, Dominique Scaravetti. A new method for extracting knowledge from patents to inspire designers during the problem-solving phase. Journal of Engineering Design, 2017, 28 (6), pp.369-407. hal-02173397

\section{HAL Id: hal-02173397 \\ https://hal.science/hal-02173397}

Submitted on 4 Jul 2019

HAL is a multi-disciplinary open access archive for the deposit and dissemination of scientific research documents, whether they are published or not. The documents may come from teaching and research institutions in France or abroad, or from public or private research centers.
L'archive ouverte pluridisciplinaire HAL, est destinée au dépôt et à la diffusion de documents scientifiques de niveau recherche, publiés ou non, émanant des établissements d'enseignement et de recherche français ou étrangers, des laboratoires publics ou privés. 


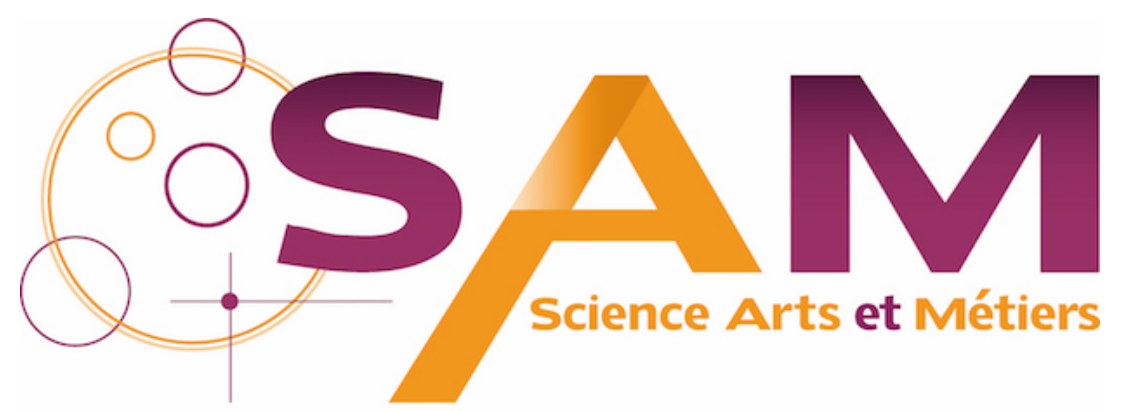

Archive Ouverte - Open Repository

\section{Science Arts \& Métiers (SAM)}

is an open access repository that collects the work of Arts et Métiers ParisTech researchers and makes it freely available over the web where possible.

This is an author-deposited version published in: https://sam.ensam.eu Handle ID: .http://hdl.handle.net/null

\section{To cite this version :}

Ulises VALVERDE, Jean-Pierre NADEAU, Dominique SCARAVETTI - A new method for extracting knowledge from patents to inspire designers during the problem-solving phase Journal of Engineering Design - Vol. 28, n6, p.369-407 - 2017 


\title{
Journal of Engineering Design
}

\section{A new method for extracting knowledge from patents to inspire designers during the problem- solving phase}

\author{
Ulises Yosafat Valverde, Jean-Pierre Nadeau \& Dominique Scaravetti
}

To cite this article: Ulises Yosafat Valverde, Jean-Pierre Nadeau \& Dominique Scaravetti (2017): A new method for extracting knowledge from patents to inspire designers during the problemsolving phase, Journal of Engineering Design, DOI: 10.1080/09544828.2017.1316361

To link to this article: http://dx.doi.org/10.1080/09544828.2017.1316361 


\title{
A new method for extracting knowledge from patents to inspire designers during the problem-solving phase
}

\author{
Ulises Yosafat Valverde, Jean-Pierre Nadeau and Dominique Scaravetti \\ I2M-IMC department, Arts et Métiers ParisTech, Bordeaux, France
}

\begin{abstract}
Nowadays, patents are more than an industrial property protection, they constitute a considerable source of information. Several approaches deal with the extraction of pertinent information from patents, some of them translate that information into useful knowledge for problem-solving purposes. However, very few methods use a physical approach and a consistent analysis of the main function in the problem definition phase. This paper proposes a new method to inspire designers with ideas and analogous solutions. The objective is to contribute to solve complex technical problems by exploiting knowledge found in patent documents. The method is divided into three sections: problem definition, research and analysis, and innovation. The first two sections use iteratively a knowledge base formed by pertinent keywords related to the problem context, physical keywords from functional decomposition and physical analysis, and technological keywords recovered through patent analysis. In the third section, interesting patents are classified in a structured discovery matrix from the physical phenomena involved which are crossed in accordance with the related techniques found. The method is supported by a physical effects database of energy conversion and by evolution trends of technical systems. A deep offshore biphasic separator illustrates the method.
\end{abstract}

\section{ARTICLE HISTORY}

Received 12 July 2015

Accepted 3 April 2017

\section{KEYWORDS}

Innovation; patents; keyword-based; energy-based; problem-solving

\section{Introduction}

The search for solutions to increasingly complex technical problems has become a key focus for companies in a competitive world. Some solutions to industrial problems can be found by looking for knowledge using different information sources such as patent databases, journals, etc., and all those available by search engines. Innovation and creativity are a central point for industries seeking innovative solutions to their problems. Various methods and techniques such as brainstorming, benchmarking, Delphi, 6 sigma, check-lists, etc, have been developed to address this issue (Chulvi and Vidal 2011). In particular, the knowledge in patents has been exploited by different methodological approaches to support problemsolving in an innovative way, such as Quality Function Deployment (QFD), Value Analysis (VA), Theory of Constraints (TOC), Axiomatic Design (AD), etc. (M. Li et al. 2013). Today, it is clear that patents not only play the role of legal instrument of industrial property, but they 
are exploited for commercial and strategic purposes, to provide a competitive advantage to industry. White (2010) states that patents disclose information not published in scientific journals or conference proceedings and indeed $80 \%$ of the information contained in patents is not published elsewhere.

Advances in the field of artificial intelligence have led to the development of computer tools and methods that reduce or even eliminate human intervention. Some of these computational methods are used for Information Retrieval (IR), information analysis, and for knowledge analysis. In the literature we found a wide range of methods, tools, and techniques which are useful in the context of patent analysis and patent exploitation. For example, query expansion methods improve the relevance of results by reformulating the user's initial query in IR activities (Gomez 2010). In the knowledge discovery domain different methodologies extract useful knowledge from data. Their main objective is to recover new knowledge rather than merely extract information; techniques such as data mining and text mining are used for these purposes (Melucci and Baeza-Yates 2011). Based on computational linguistic science, Natural Language Processing (NLP) extracts, analyzes and represents the meaning of electronic documents. Current NLP research seeks to improve the treatment and understanding of human language by computers, in order to facilitate interaction between them and humans (Anne and Sthephen 2009). Closely linked with the above methods, Machine Learning (ML) explores the construction and the study of algorithms that can learn and make predictions about the data (Stalph 2014). Finally, ontologies are used to represent the real world in computer programmes. They can be regarded as mediators in knowledge representation by means of concepts (Jakus et al. 2013).

In relation to patent search, a proper keyword selection is a critical part of the process in order to achieve relevant results. To refine the recovery of valuable patents, techniques such as brainstorming were used to select pertinent keywords before launching searches. But even experienced engineers might be undecided about this important selection. If appropriate keywords are not selected, then patents found can be numerous (unfocused research) or few (poorly targeted research). This selection is usually determined by the keywords used in the description of the invention in patents (different writing styles, the way the invention is described, multiple languages, the use of different terms to protect the invention, etc.). Compiling a good portfolio of relevant keywords to launch the search in a huge patent database is a difficult task (Y.-R. Li, Wang, and Hong 2009).

Patent search through the International Patent Classification (IPC) or other types of classification, facilitates retrieval of relevant patents or groups of patents. However, some authors argue that the classification is too general or too specific (Tseng, Lin, and Lin 2007), its use is mostly confined to the identification of a specific sector (Narin 2000), in the context of technological knowledge mapping using the IPC makes it difficult to link patents to a specific economic activity (Costantini, Crespi, and Curci 2015), and for TRIZ users (Theory of inventive problem solving [Altshuller 1994]), the IPC fails to satisfy their requirements (Loh, $\mathrm{He}$, and Lixiang 2006) because they are more interested in analogous inventions in other fields that solve the same problem (or contradiction) (Verhaegen et al. 2009).

Various authors are working on the pertinent selection of initial keywords, as in the case of Costantini, Crespi, and Curci (2015). Their approach in a complex and cross-cutting technological domain (where there is a complex definition as regards their technological and dynamic characteristics) seeks to improve how patent data are currently organised in patent databases. Their method is based on the relevance of selected keywords rather 
than the IPC-based codes. The process of keyword selection is based on a thorough study of the problem context, their database consists of keywords related to goods, services, commercial and scientific names of final products, keywords of the production value chain, etc.

Nevertheless, in the context of problem solving, it is essential to take into account technical and physical aspects in order to build a more exhaustive keyword database and therefore more relevant searches. In this regard, the approach of Russo and Montecchi (2011b) is relevant since they consider not only keywords related to the main function of the studied system, but also physical keywords. Through three creativity approaches (Linguistic - semantic relations; Engineering - TRIZ inventive solutions; Multi-visional - abstract vision of the problem) they target pertinent keywords to search for patents effectively. These keywords are completed by merging existing databases of physical effects. Their approach has its limits in defining the main function of the problem (system, product, etc.). This definition and the subsequent selection depend entirely on judgment and user experience. On the basis of a poor definition, their method and therefore the results will be adversely affected.

To address these needs, our methodology aims to improve the selection of initial keywords through an in-depth analysis of the initial main function of the study. We propose an energy based functional decomposition, known as the CTOC method (Converter, Transmitter, Operator, Control / Command) (Pailhès et al. 2011) and a detailed physical analysis. A better physical analysis of concepts found in patents will increase the number of search keywords and improve their relevance. This analysis should also open the way for new evolution opportunities. Our aim is to improve the search for information, and transform the information retrieved into useful knowledge for identifying potential evolution opportunities of the technical system in question. The originality lies in a detailed physical analysis using functional decomposition. A database of energy converters and the evolution trends of technical systems support the method.

This paper complements our previous work detailing each stage of the proposed methodology (Valverde et al. 2014). Particular focus is on the patent classification methods (discovery matrix) and patent analysis through evolution trends. We show the first innovation hints in a complex technical problem. Our application case concerns the improvement of a biphasic separator deep offshore.

The rest of the paper is organised as follows. Section 1 gives a general overview of patent analysis and patent exploitation methods and delves into criticism of existing methods. In section two, we present our methodology divided into three stages (definition, analysis, and innovation). The first stage defines the function to be satisfied and a thorough analysis of what already exists. The second stage describes functional decomposition analysis, retrieval of relevant physical phenomena and relevant parameters, followed by the classification method. The third stage deals with evolution opportunities and our innovative approach. Section three will show the methodology applied to our application case. We will conclude in section four with the discussion of this article and future prospects.

\section{Patents as source of information, knowledge and inspiration}

The concept of information, which etymologically comes from the Latin word 'informare' (to inform), means 'to give form to' or 'instruct'. From an information science 
perspective, the information must affect and transform the state of the recipients' knowledge when it is perceived. Knowledge is the awareness of understanding of someone or something, i.e. the facts, information, descriptions, or skills acquired through experience or education by means of perception, discovery and learning (Ingwersen and Järvelin 2005).

\subsection{The significance of patents}

Patent documents are a valuable reservoir of technical and commercial knowledge (B. Yoon and Park 2004); they are a potential source of knowledge location, and they contain a large quantity of technical information not available elsewhere (Fantoni et al. 2013). Their fundamental role of supporting design activities has been extended and they now provide existing design solutions to various problems; they are also an important source of technical knowledge (Russo and Montecchi 2011b).

Patents often have interesting aspects hidden inside texts, and if they are carefully analyzed, they can show technological details and relations, reveal business trends, inspire novel industrial solutions, or help make investment policy (Cavallucci, Rousselot, and Zanni 2011). However, searching for patents may return a long list of patent documents. Manually locating innovative patents in a large database through reading them one by one is a time-consuming process (Z. Li et al. 2012) as they are lengthy and rich in technical terminology such that it takes a lot of human effort for analyses. Effective information extraction is made even more difficult because patents are typically written in their own lexicon, style, and strategy in describing their inventions (Russo, Montecchi, and Ying 2012).

For these and other reasons, patent engineers, product designers, decision-makers, etc., are waiting for methods, techniques, and automatic tools, that will assist them in the task of accessing the knowledge contained in patent documents.

\subsection{Extracting information: overview of various patent analysis methods}

In order to analyze patents and then extract the pertinent information contained in them, several authors are using scientific metrology. It can be used to analyze, quantify and measure communication phenomena to make specific and formal representations of their behaviour for explanatory, evaluative, and administrative purposes (Bellis 2009).

In patent analysis, the most frequently used tool is the citation analysis (bibliometric analysis on patents). Some drawbacks identified by B. Yoon and Park (2004) are the difficulty of grasping the overall relationship between patents, taking into account only citing and cited information, it considers only the existence or frequency of citations, and it is a time-consuming task. They propose an alternative approach to overcome these limitations. Their method is based on network analysis and it is completed by text mining techniques. They start extracting keywords from patents, and then they perform a measure of similarity between patent documents. They state that an intuitive and comprehensive analysis is possible from the visual model of the network. Chang, Wu, and Leu (2012) proposed using frequency of keyword occurrence and Network Patent Analysis (NPA) in order to develop a relationship between patents and to investigate technological trends in a given technological area. The authors claim that even non-experts in the study field can identify technology key points. 
Another relevant aspect used in some patent analysis methods is the notion of patent family (a group of related patents that describes the same invention or a portfolio of similar patents in a company). Patent families are used in the context of design activities to deploy a corporate patent strategy and allow the exploitation of the most representative patents. There are also some limitations linked to patent families, i.e. various evaluation criteria from different countries, different translation problems, poor description of patent claims, etc., which considerably restricts the selection of interesting patents. Once again, a hybrid method proposed by OuYang and Weng (2011) integrates patent families with patent citation analysis. Their method focuses on patent circumvention (or design-around), the authors affirm that patent citations facilitate the discovery of evolution of technological development, and the frequency of patents that are cited reveals technological importance. Their approach needs several experienced experts (in the field to be covered by the study) to assess which are the representative key patents of the patent family.

As regards to information extraction methods, several authors seek to extract functions using the different computational tools and techniques mentioned above. A function translates the action that any system performs; it is expressed by a verb and an object (complement). Expressing the function of a system allows the use of innovation and design methods defined in ISO 9000 or those developed by various research laboratories (i.e. I2MIMC) or by the many consulting firms. To extract information about functions from different sections of patent text (title, abstract, description and claims), Park, Yoon, and Kim (2013) use NLP and functional similarity analysis. In the same vein as in the above methods, a group of experts defines the specific function of a technology; all patents associated with this technology are then collected.

Other authors use semantic algorithms to analyze the structure of sentences, find relationships between words and the meanings of word combinations. They seek to find Subjects, Actions, and Objects of the actions (SAO structures) (Cascini and Risonne 2001). In the analysis of patent texts, SAO structures are commonly used to represent the functions related to technologies. Using NLP, Park et al. (2013) extract SAOs from a collection of relevant patents in a patent intelligence context. In their recent work, they add text mining techniques and TRIZ trends, which are used as evaluation criteria to assess the technology found in patents (Park, Ree, and Kim 2013).

In a design context, many authors use the Function - Behaviour - Structure (or FBS Model). According to John S. Gero (1990), the result of the design activity is the design description. Based on the concepts proposed by Gero, the FBS model is an ontological conceptualisation of design objects divided into three categories (Function, Behaviour and Structure variables) (Gero and Kannengiesser 2004). For instance, in the context of New Product Development (NPD), Fantoni et al. (2013) propose a tool to accelerate and facilitate human analysis of the large corpus of patent documents. Another relevant example in a problem solving context is the modified FBS ontology proposed by Russo and Montecchi (2011b). Their ontology is called 'FB-Ph-S'; it is composed of the Function (systems main function), the behaviour (sequential change of states), the physical effects (transition from one state to another) and the structure (description of the systems behaviour and its relations). The authors assert that this ontological approach based on physical keywords and keywords associated to behaviours produces better results than traditional approaches (80\% reduction in irrelevant patents) (Russo and Montecchi 2011b). 


\subsection{Using knowledge: overview of various patent exploitation methods}

Many approaches interested in patents seek to transform information into useful knowledge for different purposes (i.e. design activities, technology planning, forecasting, etc.).

In a technological context, Choi et al. (2012) propose interconnection diagrams, known as 'TechTrees', to show the relationships between products, technologies, and technology functions. They look to identify strategic technologies to support decision-making in a given market. Jeong and Yoon (2015) built a patent roadmap (a tool for forecasting and planning patents) based on a technology roadmap (a means to link technology and other resources to future products) for technology forecasting and patent planning. According to the authors, their method enables managers to establish patenting strategies in order to achieve a valuable core patent that has the potential to become a business model.

Transforming the content of patents into legal, commercial, and technical knowledge is possible through Patent Intelligence methods. They are broadly used by those who want a competitive advantage in technology markets. Bécue, Flamand, and Frigant (2013) claim that a financial and regulatory view enriches the analysis because it is possible to measure technological maturity and identify actors with innovative ambitions, and also in addition, this view assists in the discovery of different paths of innovation. Some patent intelligence approaches are only based on the frequency of occurrence of previously defined keywords, which leads to a lack of representation of key technological concepts and inventive knowledge. They can be completed by Patent Maps, Patent Landscape and Patent Networks using semantic analysis and SAO structures in order to identify technological trends for Technology Planning (Park, Kim et al. 2013).

Another important field for the industry is determining whether a particular action, such as testing, launching or patenting a new product, can be done without infringing valid intellectual property rights of others. Patent lawyers face this problem commonly known as Freedom-To-Operate (FTO). Fu et al. (2013) propose a computational method that exploits patents in order to support patent lawyers in getting a faster and fresh snapshot of the space of prior art, and even points to patents most relevant to a proposed new product.

We found some exploitation methods concerning technology foresight, technology forecasting, etc., in which researchers attempt to anticipate the next technological advances or anticipate the generic or specific direction of the evolution of technology. These methods are usually completed by the evolution laws of the TRIZ theory (Section 3.3.2), developed by the Russian scientist Genrikh Saulovich Altshuller (1984b).

For instance, in order to predict technological improvements in a product family, Verhaegen et al. (2009) propose a patent categorisation based on Altshuller's laws. Their approach starts retrieving a collection of patents from the IPC, then they compare the relevant information extracted with TRIZ laws using adjectives found in patent texts (by means of part of speech tagging). The authors seek to support design engineers in the product design phase. Other researchers compare TRIZ laws with the binary relationships between patents (extracted through NLP and Semantic Similarity) (J. Yoon and Kim 2011), (Yoon and Kim 2012). Some other authors classify patents according to the inventive principles of TRIZ theory (through machine learning techniques) (Loh, He, and Lixiang 2006), and according to their level of invention (LOI) in order to characterise the creativity of design concepts (using ML, NLP, Data Mining, and Patent Citation Metrics) (Z. Li et al. 2012). 
Finally, the Laboratory of Design Engineering (LGeCo) has worked in the modelling of TRIZ, with the aim of providing assistance to inventive design experts (Cavallucci and Khomenko 2007). The Inventive Design Method (IDM) is an extension of TRIZ, developed to complete and clarify the concepts involved in the TRIZ theory (Souili, Cavallucci, and Rousselot 2015a). The authors formalised an ontology called the IDM ontology, which is generic and therefore intends to be applicable to all patents irrespective of their fields. Souili and Cavallucci (2012) extract, from patent documents, knowledge such as problems, partial solutions and parameters. Using linguistic markers and NLP techniques, the authors match and extract knowledge relevant to the IDM ontology (Souili, Cavallucci, and Rousselot 2015b), (Souili et al. 2015).

\subsection{Providing inspiration: overview of some keyword-based patent methods}

The inspirational process is a crucial part in the design activity. It can be defined as the search for stimulation of originality and creativity. Setchi and Bouchard (2010) establish that the observation and interpretation of different sources of inspiration (e.g. patents), allow designers to form vocabularies and terms. Using semantic-based algorithms and ontologies, the authors demonstrate that a concept-based search, combined with content-based image retrieval and keyword-based search, is a useful tool for providing high inspirational value to designers.

In the context of keyword-based methods, Y.-R. Li, Wang, and Hong (2009) extract significant-rare keywords using text mining techniques and chance discovery (the discovery of information about an important event [Yukio 2003]). They select and extract the keywords less frequently used by scientists and technologists in patent drafting. The authors claim that through a repertory of additional keywords, interesting results are obtained for NPD, patent infringement, technology management, etc. In the context of NPD, Tian, Zhiping, and Zhengyin (2013) extract technological keywords automatically in order to provide designers with relevant information. Using data mining and semantic annotation (tagging) they construct their knowledge base, which complements the traditional keyword and IPCbased searches. Lee, Yoon, and Park (2009) also consider patent databases as sources of innovative ideas; they seek to discover undeveloped technological fields from the patent databases. Their approach is based on keyword vectors extracted by means of text-mining techniques, for the creation of keyword-based patent maps. These patent maps are constructed from the similarity of keywords found in each analyzed patent. They are looking to identify promising opportunities for New Technology Creation (NTC). In the same vein, Park, Ree, and Kim (2013) realised that industrial technologies belonging to different application fields can be linked through a functional perspective because the functions used are generally similar. They use this knowledge in technology transfer activities.

To get inspiration to come up with innovative solutions for industrial applications is possible by several proven approaches, such as design-by-analogy, analogical reasoning, analogical transfer, etc. Fu, Chan, et al. (2013) propose a design-by-analogy facilitation tool to find automatic design solutions from other domains in order to gain inspiration or insight for the design problem at hand. The authors use a computational text analysis tool (Latent Semantic Analysis, LSA) and a Bayesian-based algorithm to extract contextual similarity of documents and words. They build patent regions formed by pertinent keywords extracted by LSA. These keywords are formed by verbs to describe functionality (verbs correspond to 
what something does or should do) and by nouns to describe components, applications, or elements of a design (nouns represent attributes of the patents). They establish that by just looking at the titles of these categorised patents, the user can deduce analogous functionality that might inspire a designer who is looking for different ways to affix something to something else (Fu, Cagan, et al. 2013). Along the same line, Cheong et al. (2011) propose a method that allows engineers a better access to biological analogies and stimuli for engineering design. They state that humans have borrowed many ideas from biology for design, most of them inspired from chance observation. Representing generic taxonomies of engineering functions, and product functionality as verbs and nouns, the authors translated them into biologically meaningful keywords (a keyword that may be more effective in searching biological text than the corresponding engineering keyword). These keywords could serve as a thesaurus for engineers to find biological analogies relevant to their design problems. The authors extend their method using a rule-based computational technique, to identify biological analogies that contain causal relations (how one function is enabled by another function) (Hyunmin Cheong and Shu 2014).

\subsection{Assessment and improvement opportunities}

In the various methods discussed above, we have identified that most of them start with the selection of pertinent keywords, or with the selection of the main function of the study, which is then translated into relevant keywords. Normally, the final results are influenced by this initial selection We noticed that self-criticism of authors concerning performance, accuracy, relevance, etc. of their methods is linked to the lack of a structured approach in correctly selecting the main function and the initial associated keywords. We have also observed that many methods depend on the IPC for launching their initial patent search; we have argued that retrieved patents based on this classification alone may limit the results in other interesting areas (at least in a problem-solving context).

Such is the case in the method of Tian, Zhiping, and Zhengyin (2013), which seeks innovative solutions from the extraction of technological keywords. The authors acknowledge that their approach lacks accuracy and quantitative criteria to support experts in pertinent keywords selection, and moreover, their knowledge base is built on the basis of subjective judgments, which makes their technological classification inaccurate. This is also the case with Park, Ree, and Kim (2013), whose method aims to identify potential areas of application of a given technology and is also used for technology planning matters. Firstly, their search queries are composed of keywords from the IPC and bibliographical and textual information; an improvement in these queries and a better selection of initial keywords can lead to better outcomes after processing patent documents. Secondly, the definition of the function performed by the experts remains ambiguous due to the lack of a structured method (Park, Kim et al. 2012). A further example can be found in the method of Russo and Montecchi (2011a), [(Russo and Montecchi 2011a), (Russo, Montecchi, and Ying 2012)] seen previously. Indeed, very few patent analysis and exploitation methods integrate physical effects into their knowledge base. Their method assists product designers in the creativity and problem-solving phase, they aim to improve existing tools for intelligent design and implement solutions oriented towards new technologies. Once again their method is limited in the system's main function selection, because this depends entirely on users' judgment and experience. 
Although the methods discussed here are robust in the integration of methods, techniques and computer tools, we insist that if the main function is not properly chosen, even the most effective method could be oriented in the wrong direction, leading to irrelevant results. These kinds of approach need to be structured through inventive design methods in order to effectively address problem-solving tasks. A better physical analysis of concepts should increase the amount of keyword research and improve its relevance. This analysis should also reveal some evolution opportunities.

Lastly, we are also aware of the importance of methods, techniques and tools from artificial intelligence in analyzing patents. It is true that manually analyzing and examining patents is a time-consuming and laborious task (Chang, Wu, and Leu 2012), and for this reason, better approaches to extracting information from patent texts (written in natural language) are needed. However, there are still shortcomings in extracting information from patent texts, and this has led to the use of new models, improved ontologies, new methods, etc. In this article we do not address these issues; our aim is to complement the existing analysis and exploitation methods with our new and original view.

Figure 1 summarises some analysis and exploitation methods found in the literature. Two primary questions are presented in order to visualise what exists and the perspective of several authors. First, the question 'how?' shows the methods and techniques commonly found and the question 'why?' describes their objectives.

\section{Proposed method}

We propose a new methodology based on an energetic perspective and on the pertinence of selected keywords to help designers in problem-solving tasks. We take into account the following issues:

- A method to select pertinent keywords related to an initial comprehensive study of the problem context,

- A structured approach to analyze the problem's main function and its translation into pertinent keywords incorporating a detailed physical analysis,

- A method of analysis and classification of patents by means of discovery matrices,

- A method to deduce the system's evolution opportunities by incorporating improved evolution trends.

The block diagram in Figure 2 details our method divided into three stages. The first stage is based on the context of the problem (or system of study), and is divided into two phases: a detailed analysis of the main function and an extensive search of what exists. We seek to analyze the main function through a functional perspective, and to identify all available resources. We recover all initial keywords related directly to the problem, to the context, and to the 'life stages', i.e. external environments, fields of application, involved companies, etc. Then, using the initial keywords recovered we form a group of queries with which to search for new concepts by means of the existing search tool. With this tool we are able to expand the research field to scientific journals, open access articles, patent databases, and search engines (Figure 3). Once this 'definition' stage is completed, a detailed analysis of collected concepts can be conducted in the next stage. 


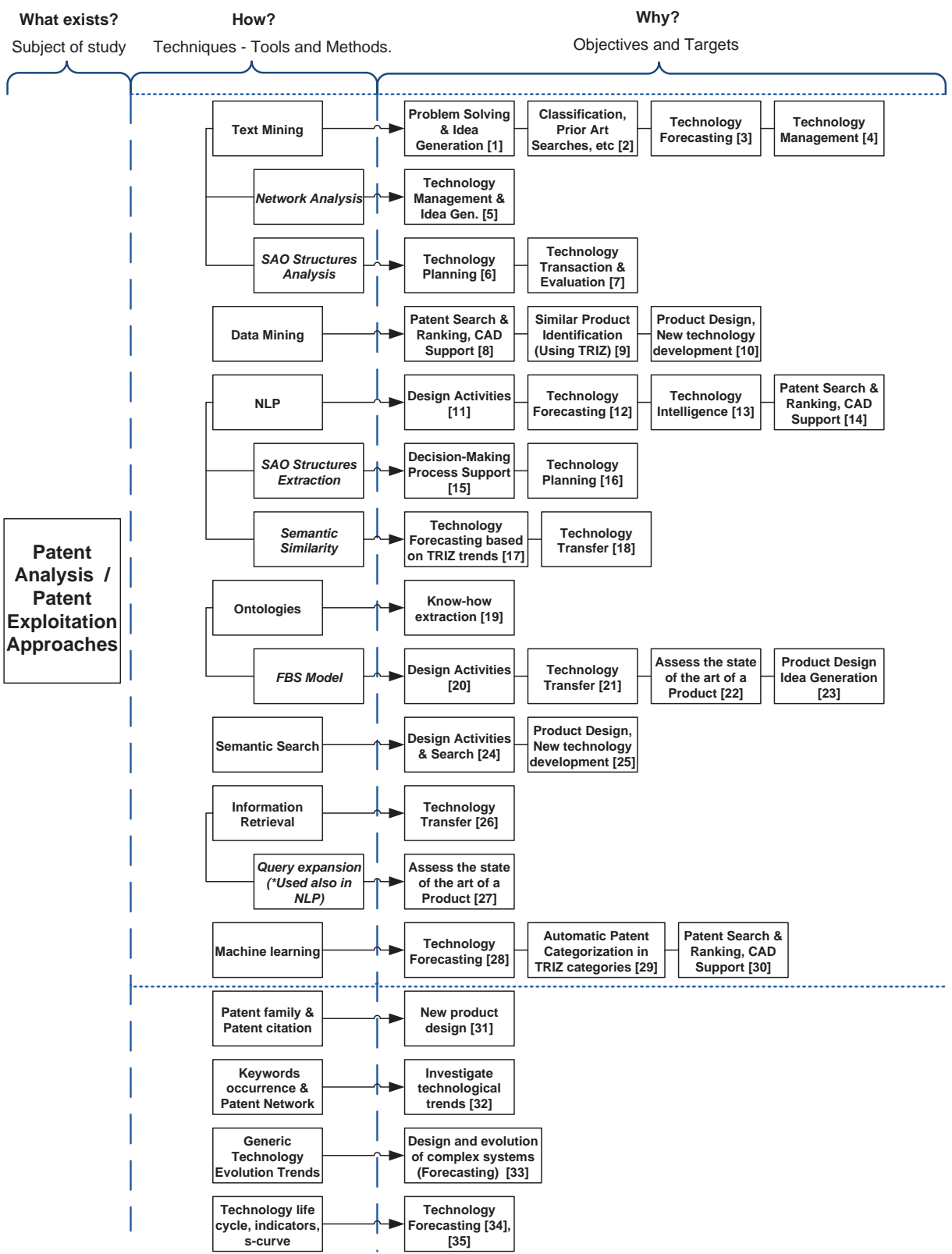

[1] - (Paul Armand Verhaegen et al. 2011); [2] - (Tseng, Lin, and Lin 2007); [3] - (Gao et al. 2013); [4] - (Y.-R. Li, Wang, and Hong 2009); [5] - (B. Yoon and Park 2004); [6] - (Choi et al. 2012); [7] - (Park, Ree, and

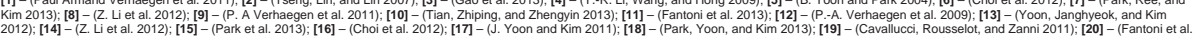
2013); [21] - (Russo, Montecchi, and Ying 2012); [22] - (Russo and Montecchi 2011); [23] - (Russo, Davide, and Montecchi 2011); [24] - (Montecchi, Russo, and Liu 2013); [25] - (Tian, Zhiping, and Zhengyin 2013); [26] - (Russo, Montecchi, and Ying 2012); [27] - (Russo and Montecchi 2011); [28] - (Cunn
Wu, and Leu 2012); [33] - (Mann 2003); [34] - (Yu and Fan 2012): [35] - (Gao et al. 2013)

Figure 1. Synthetic map of various patent analysis and exploitation methods found in the literature. A dashed line and a dotted line are used to indicate separation between information blocks.

This iterative stage is based on a detailed and structured analysis of patents and their main function. The exhaustive search for relevant keywords begins with an analysis of the required functional flow to carry out the function. The expected operation is a functional 


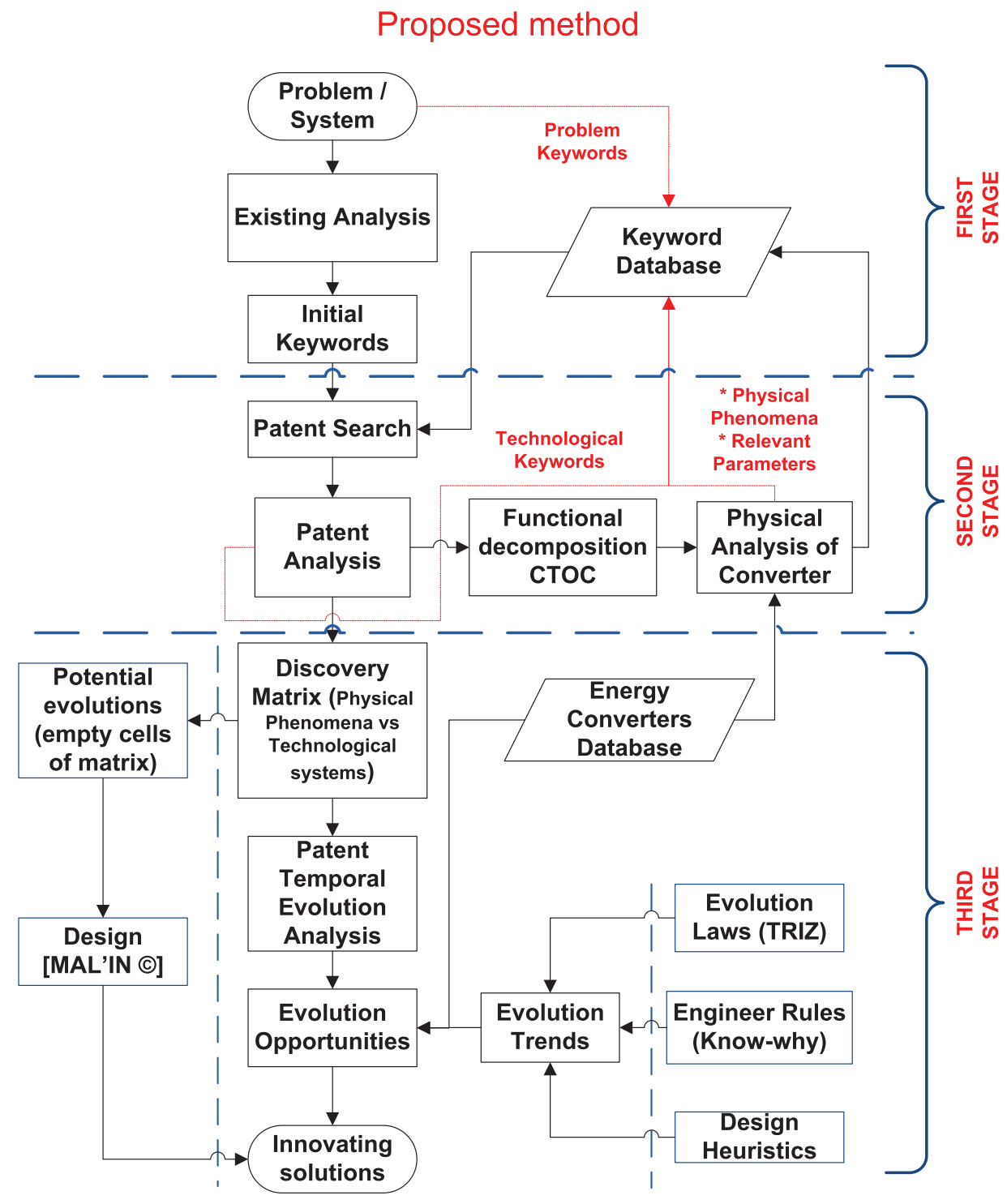

Figure 2. Block diagram of proposed method. Dotted line arrows indicate the entrances to the keyword database. Dashed line arrows indicate the divisions between stages.

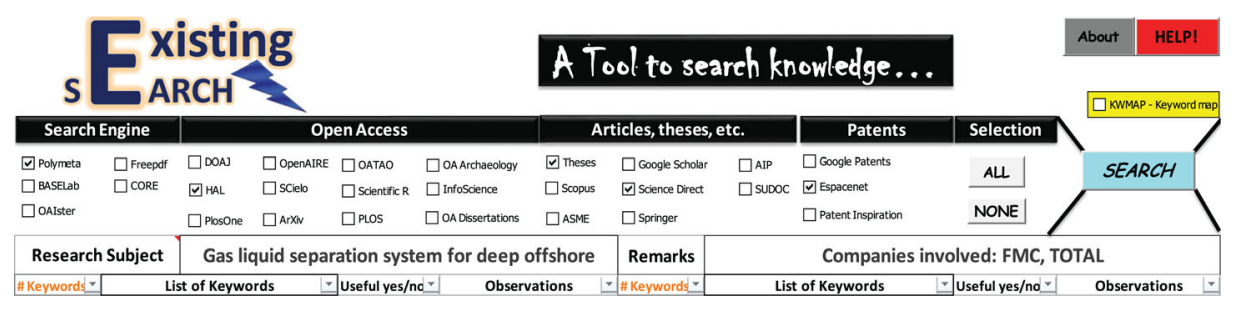

Figure 3. Snapshot of the 'Existing Search' tool. 
analysis that will lead to the selection of imposed or implied physical phenomena. The physical phenomena, the improvement techniques, and related keywords are the basis of knowledge. Functional decomposition (CTOC method) allows us to access different keyword fields from the initial keywords (Pailhès et al. 2011). These keywords come from different types of converters which can be preselected (Section 3.2), allowing us to search for patents in different fields. The search for patents from keywords listed in the knowledge database is then carried out using traditional patent databases. Our research is oriented and framed. The designer selects and classifies relevant patents, seeking to deduce evolution opportunities and thus move toward innovative solutions.

The third stage concerns our innovative methods, in which we introduce the discovery matrix and our proposal for evolution trends of technical systems. We seek to identify evolution opportunities and innovation axes by exploiting patents through the discovery matrix. The matrix can also be exploited by analyzing the empty cells (concepts not found or non-existent) with traditional innovation aid methods based on TRIZ theory and supported by software tools such as MAL'IN, Goldfire Innovator, CREAX, etc (Zouaoua-ragab 2012). A database of the physical effects of energy conversion complements the evolution opportunities and the physical analysis of converters in the second stage.

\subsection{First stage: problem definition}

A problem is a matter to be resolved in any field, which arises with a number of challenges and obstacles. According to Nickles (1981), in a certain subject, two interveners can have the same problem without knowing the same things about it and can approach this problem from different ways, even from different fields. Problems can be reformulated significantly (conceptually) in different ways, completely reformulated, processed, or reduced to other problems (while retaining the essential). Problems can also be modelled in other problems, even when the data or the objects are different. Normally, complex reasoning occurs in problem-solving contexts.

The industrial problem to be solved can be written in different ways: by expressing the initial problem situation synthetically (Nadeau and Pailhès 2010), by expressing the problem in the form of a verb plus complement (what we want to achieve), by providing a full description of the functional requirements (for customer satisfaction requirements) (El-Haik 2005), or through a cause/effect perspective (Calle-Escobar et al. 2014).

\subsubsection{Problem / system analysis}

All keywords related directly or indirectly to the problem in question are recovered, and they start consolidating the keyword database. We produce a detailed description of the problem (or function to study), which is then described by several main keywords. These keywords can be enriched with keywords relating to the problem, the constraints, the life stages, external environments and existing resources. All possible queries will be listed on a chart of the existing search tool, and they can then be used for launching automatic searches through several websites.

\section{(1) Constraints}

In design terms, Sallaou (2008) stated that constraints reflect limitations on the variables of the problem. According to Suh (1990), two classes of constraints are pertinent, 
input constraints (limits, weight restrictions, size, cost, material, performance) and system constraints (imposed by the operating environment, i.e. physical behaviour, production capacity, etc.).

All the constraints associated with the problem/system should be taken into account; they contribute to the analysis of the environment and context of the problem. The constraints also provide keywords that may improve and focus the information search.

\section{(2) Life stages, external environments and existing resources}

Throughout its life cycle, a system encounters specific life stages or situations. Designers should enumerate and analyze these situations (or phases), in order to define service functions that the system will carry out and the constraints that it must undergo. A life situation concerns a global phase characteristic of the product life cycle; it will be described by a succession of elementary or dynamic events (succession of 'significant moments') (Nadeau and Pailhès 2007).

In every life stage, a system also encounters external environments that will constrain it and impose specific functionalities. They concern the system (or product) environment, i.e. fluids, energy supplier, user, environment, etc (Nadeau and Pailhès 2010).

For every life stage there are also resources to identify and to list. The resources constitute a substantial source for designers and allow them to think differently, unconventionally or from a new perspective ('Thinking Outside The Box') (Savransky 2000). Resource analysis identifies problems related to the materials used, existing or produced energies, interactions between components and interacting components, the system architecture, untapped resources, and waste. In summary, the resources include everything that can be used in the design of a system/product.

\subsubsection{Analysis of what exists, initial keywords and tools}

Searching for what exists is a traditional activity performed by any individual wishing to be informed about a particular subject. To support this activity, several search engines, specialised websites, databases, etc. are available. In an initial search for concepts, chosen keywords may be inaccurate. Gomez (2010) mentions that users usually do not know how to express their queries or the best way to get relevant results. Their initial keywords may be an inadequate or incomplete representation of their needs. Several tools and methods are continuously being developed to complement and expand user queries.

In order to achieve a more pertinent search of what exists, we have proposed a structured and iterative search approach (by using the results in the new search queries), which integrates relevant information sources. We start by listing all keywords derived from the synthetic expression of the problem and all keywords related to the constraints, life stages, external environments and resources. Next, after an initial search for concepts, new keywords are added to initial keywords through interaction with preselected websites. Finally, the initial keywords are refined by analyzing the results, that is, if keywords do not give consistent results, it could mean that the query was not well formulated or the selected keywords are not relevant for the problem. This loop will be repeated until the user considers he has enough information for analysis in the second stage.

We seek to structure the process of searching for pertinent documents and to provide users with a tool (Figure 3 ) that can produce a robust state of the art by searching in different 
fields, multidisciplinary information sources, relevant thesaurus and keyword map sites, i.e. scientific journals, open access archives, patent databases, etc. This tool enables search queries to be launched simultaneously in the preselected websites. The user keeps track of keywords used and any comments (usefulness and relevance of the keywords) while continuing to use new keywords (physical keywords for instance) or new keywords found in the suggested websites.

\subsection{Second stage: research and analysis}

In this stage, we use the keyword database to search for interesting concepts in patent databases. Patent analysis allows us to recover technological keywords that complement the knowledge base and serve to achieve more accurate iterative searches. Functional decomposition and physical analysis dissect the main functions of the selected concepts. Physical keywords are then recovered and integrated into the keyword database. The recovered relevant patents are classified on a discovery matrix constructed from the intersection of the physical phenomena and technological systems found. This matrix will be exploited in the last stage to deduce evolution opportunities.

\subsubsection{First patent search and patent analysis}

We have defined a structure to classify retrieved keywords in our keyword database. For us this classification of keywords is more than a mere database, thanks to the user interaction which classifies keywords in a predefined structure; this database constitutes the knowledge base.

We propose a structure that takes into account only some elements of the part of speech (word class). The proposed structure is divided into seven categories including nouns, verbs, adjectives and adverbs. From the parts of speech, we do not use the pronouns, the interjections, the conjunctions, the determiners, and the prepositions. We simplify the search queries taking into account the following elements: nouns/names (to design a thing or a concept), verbs/adjectives/adverbs (all keywords expressing an action or that modify a noun or pronoun, or that clarify the meaning of a verb, an adjective, etc.), physical phenomena (all keywords describing the physical laws, physical quantities, physical effects, energies, etc.), technological systems (keywords representing technologies, process, techniques, etc.), type (i.e. system, device, apparatus, etc.), companies/firms and complements (all optional nouns that provide a more detailed description of the problem).

Another tool allows users to select the keywords and generate different search queries that will be launched in Espacenet interface. We use Espacenet services first because it has over 90 million patent documents from more than 80 countries (EPO 2016), and second, managing queries in Espacenet facilitates integration of our keywords. In other patent interfaces, using all elements of the part of speech can influence the number of results found. We are looking to use only the essential and key elements for recovering pertinent patents by proposing queries that are parsimonious and as exhaustive as possible. The search query should be reformulated if patents found have no relevance or bear no relation to the main function.

We now search for a maximum of patents related to the problem in question and the main function initially detailed. Patent documents are analyzed manually. First, the user selects the patents to be analyzed by looking at the relevance of document titles. Next, 


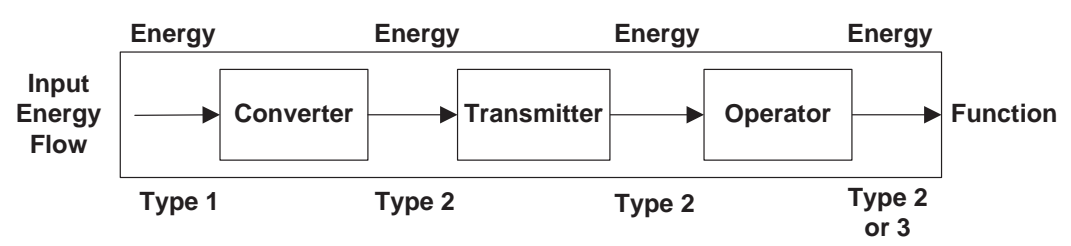

Figure 4. Functional decomposition (CTOC method).

analyzing only the abstract may tell users if patents are related to the main function studied, the main technologies employed and the physical phenomena involved. Some authors consider the abstracts as the heart of the patent, because they have the most meaningful and concise textual information about the inventions (Chen, Tokuda, and Adachi 2003). A deeper analysis of other sections (description, claims, etc.) will be performed when the patent is classified in the discovery matrix.

\subsubsection{Energy-based functional decomposition}

We use functional and physical analysis to associate keywords with relevant physical parameters. Pailhès et al. (2011) propose an energy approach based on functional decomposition of systems. Their energy perspective is based on the TRIZ law known as 'the completeness of system parts'. They consider (along the lines previously defined by Pahl and Beitz [1988]) that all flows related to functioning (energy, matter and signal) can be reduced to energy flows. These flows are grouped under the term 'functional flow', and together with the components and interfaces that ensure their transformation and their transport until the action is completed, they are just and necessary to achieve the function.

Pailhès et al. proposed functional analysis CTOC (Converter, Transmitter, Operator, Control / Command). For a given function, four main elements can be distinguished to carry out the action. The converter changes the available energy into usable energy. The transmitters transmit and/or adapt this energy to the operator, who performs the action. The control/command components provide the required performance. The functional flow consists of the delivery of power through the components. The functional flow and the components that it crosses are necessary and sufficient to carry out the function (Figure 4).

The final energy that performs the action may be different from the outgoing converter energy. The operator itself is an energy converter if the energy which performs the action is different from the energy transmitted by the transmitter. For energies of identical input/output, we can use different types of converters. These findings become a source for expressing new keywords that will make the eventual patent search possible.

Thus, we observe that the converters are the essence of the functioning of the system, which is an important finding for our research. The relevant physical phenomena are linked to the converter. Moreover, for the same energy conversion (the same input / output), we can use different types of converters which leads us to new concepts. The existence of these new concepts should be verified.

Finally, the use of functional decomposition allows us to focus and direct the search by defining keywords related to the associated physical phenomena. These keywords come from physically analyzing how converters function, thus suggesting future possibilities as to 
Table 1. Examples of relevant conjugate variables.

\begin{tabular}{lllc}
\hline \multicolumn{2}{c}{ Relevant conjugate variables } \\
\hline Type of energy & \multicolumn{1}{c}{ Temporal variables } & \multicolumn{1}{c}{ State variables } & Energy flow (power) \\
\hline Mechanical (translation) & Speed $(\mathrm{V})$ & Force $(\mathrm{F})$ & $\mathrm{V} \cdot \mathrm{F}$ \\
Mechanical (rotation) & Rotation speed $(\omega)$ & Couple $(\mathrm{C})$ & $\omega \cdot \mathrm{C}$ \\
Hydraulic/pneumatic & Volume flow rate $(\mathrm{qv})$ & Pressure $(p)$ & $\mathrm{qv} \cdot \mathrm{p}$ \\
Thermal (sensitive) & Capacity flow rate $(\mathrm{q} C \mathrm{p})$ & Temperature $(\mathrm{T})$ & $\mathrm{q} \cdot \mathrm{Cp} \cdot \mathrm{T}$ \\
Thermal (Storage) & Flow rate $(\mathrm{q})$ & Internal calorific value $(\mathrm{PCl})$ & $\mathrm{q} \cdot \mathrm{PCl}$ \\
Electrical & Current $(\mathrm{I})$ & Electrical potential $(\mathrm{U})$ & $\mathrm{I}$.U \\
\hline
\end{tabular}

the evolution of other relevant physical parameters. In such cases, they become keywords for continued research and further complementing the keyword database.

\subsubsection{Converters and physical phenomena}

It is therefore possible to express the functional flow associated with conducting the function in terms of energy flow. This simplified process allows us to reconcile the design with physics-based approaches in which the input or output energy flow is expressed by energetic power (a product of two characteristic variables, Table 1).

The study of conservation laws in converter components allows us to define relevant parameters. These variables are the first keywords. We then look for the relevant physical parameters involved in the conservation laws (energy, matter, momentum). The names of the physical phenomena involved in these laws establish new keywords. Studying these laws enables us to define possibilities for increasing efficiency from the evolution of the parameters. The techniques used to vary the parameters also create new keywords.

\subsubsection{Iterative search and breakpoints}

Selecting interesting patents is a subjective activity that depends, in our context, on the user's judgment. Nevertheless, we consider some general clues for considering a patent to be pertinent, and then classify it in the discovery matrix (Section 3.2.5), i.e. it has a direct relationship with the main function of the study, it uses a particular or non-conventional technology, a physical phenomenon is used in a special way, the patent details a hybrid invention where several technologies coexist, the invention is used in an alternative field of application, it deals with one or more constraints of the system in question, or any other original related concept.

The iterative phase needs to be stopped at a given time. We define two breakpoints: the first is related to a given query, and the second to the global analysis of patents. The first breakpoint is identified when a query always brings up the same concepts (the same physical phenomena and their associated technology spotted several times), this means that patents found have the same main function and the user should search with a new query. In the second breakpoint, quantitatively the general patent analysis is stopped when the discovery matrix is completed. This indicates that most of the physical phenomena for carrying out the function have been associated with the different technologies found. If the matrix is not completely filled, it is a question of discerning if the missing crosses correspond to scientific challenges or technological impossibilities and if these bottlenecks can be unblocked or not, and if so, when? Thus, unfilled cells in the matrix are deadlocks or innovation opportunities. 


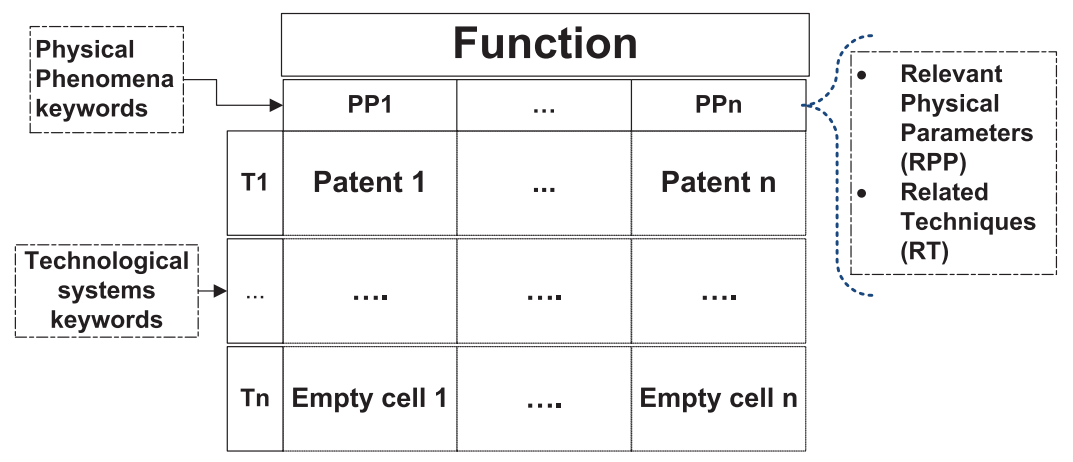

Figure 5. Concept of discovery matrix.

\subsubsection{Discovery matrix}

The discovery matrix is a tool that allows us to organise the results in a table based on viewpoints defined by the user. In Figure 5, the matrix is constructed by crossing the technological systems and the associated keywords with the types of converters to physical phenomena. Each converter includes Relevant Physical Parameters (RPP). Each RPP can be linked to one or more Physical Phenomena (PP). The improvement of each PP can then induce Related Techniques (RT). Each relevant patent is thus classified.

The first evolution opportunities are found in the empty cells, which means that the corresponding concept does not yet exist. We can also exploit the matrix from the laws of technical systems evolution (third stage).

\subsection{Third stage: innovation, opportunities and solutions}

In this stage we look for evolution opportunities and all possible solutions to the problem for further study. Once the matrix has been defined, we exploit it by a temporal analysis of patents and through the evolution laws, design heuristics and the rules of the art of engineering. We look for evolution followed by the different technological branches of the matrix and foresee the next technological leaps (in an ideal case).

\subsubsection{Exploitation of the discovery matrix s}

The possibilities for exploiting the matrix are varied, i.e. by date of appearance, by physical phenomena involved, by technology used, by scope, etc. The selected classification provides users with different kinds of information, for example, classification from a physical perspective shows the different phenomena used by the patented inventions. This classification shows which physical phenomena are used most (or least) to perform the main function.

In this article the discovery matrix is ordered automatically in a timeline, the aim being to analyze patents through our proposal of evolution trends and reaching the first innovative solutions. Figure 6 shows this concept in general terms. In some cases this kind of classification highlights obvious technological changes, i.e. shape changes, the addition of one or more components, the division of the system components, etc. In other cases, the changes are less visible, i.e. change in an operating frequency, improvement in an energy flow, the addition of materials, fibres, fabrics, etc. In all cases, a structured approach must be used 


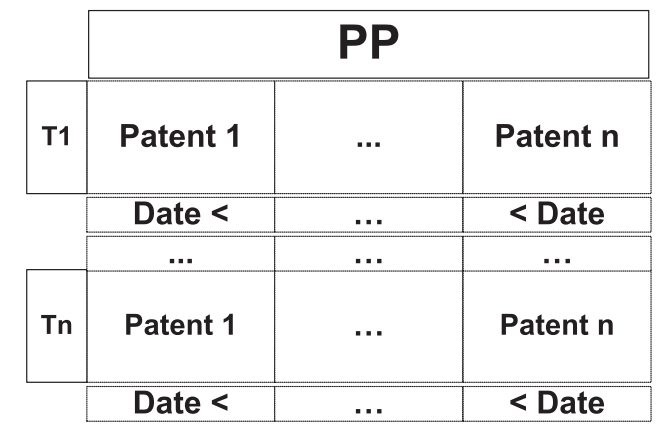

Figure 6. Concept of patent timeline.

to identify technological trends, and estimate future technological advances in patented inventions.

\subsubsection{Evolution opportunities}

The objective of exploiting the discovery matrix is, as its name suggests, discovering and identifying any opportunity to innovate in achieving the main function of the study. We have established three different axes to find and exploit the evolution opportunities of technical systems (main function to be studied). The first relates to the empty cells of the discovery matrix, the second is based on the evolution trends, and the third axis is related to the converters database (physical effects of energy conversion).

(1) Axis 1:Opportunities linked to the empty cells of the discovery matrix

Looking at the matrix, some cells will be empty. This means that the physical principle is not used in the patented technological system. It is then a question of looking for the reasons, and these can be of several types: the research is not exhaustive, the concept is in the public domain and could not be patented, the concept has not been patented, there may be a mismatch between the physical phenomenon and the technological concept used, a technological bottleneck has to be unblocked, a scientific bottleneck must be also unblocked. If a scientific bottleneck exists, it must be unblocked by research.

In the latter cases, the reasons must be sought. They may concern either the system in its functioning, or the practical implementation of the system, i.e. the manufacturing process. Overcoming these obstacles is the starting point of the system evolution. For this, we will use problem-solving methods such as TRIZ or those developed by the I2M-IMC laboratory (MAL'IN software [Pailhès and Nadeau 2007]).

(2) Axis 2: Opportunities arising from the evolution trends

In order to deduce the potential technical opportunities in the discovery matrix ordered in timeline, we have compiled the evolution laws developed by Genrikh Saulovich Altshuller (1984a), the rules (heuristics or inventive principles) proposed by A.I Polovinkin (1991), and the rules of the art of engineering. We take as a principle that technical systems obey 'trends' 
that govern their evolutions. We seek to analyze, classify, and define the evolutions that the pertinent classified patents will follow.

We have worked in design heuristics that consider the aforementioned laws and rules, to support design engineers in the inspiration, creativity and problem-solving phase (CalleEscobar et al. 2014). By adding new rules of the art of engineering, and more design heuristics, we have built different cards composed of 'evolution trends'.

(a) Altshuller's evolution laws

Altshuller having studied more than 40,000 patents, developed objective laws that describe the evolution of technical systems. He relied on his observation, patent analysis, and the study of what exists (Savransky 2000). These laws are:

L1. The law of the completeness of parts of the system

L2. The law of 'energy conductivity' of a system

L3. The law of harmonising the rhythms of parts of the system

L4. The law of increasing the degree of idealness of the system

L5. The law of uneven development of parts of a system

L6. The law of the transition to a super-system

L7. The law of the transition from macro to micro level

L8. The law of increasing the S-Field involvement

(b) Polovinkin's rules

Professor Alexander Polovinkin has proposed 121 rules, grouped into nine sections, which are derived from innovation principles, resource management, and the multidisciplinary experience of design engineers (Polovinkin 1991). Complete rules and their respective subdivisions can be found in the work of Carvalho, Wei, and Savransky (2004). The nine groups of Polovinkin's rules are:

R1. Transformation of shape

R2. Transformation of structures

R3. Transformation in space

R4. Transformation in time

R5. Transformation of movements and mechanical actions

R6. Transformation of materials

R7. Differential resources

R8. Quantitative modifications

R9. Transformations related to evolutionary trends

Polovinkin's rules have the advantage that they can be implemented without a defined methodological framework. Their application enables a broad spectrum to be covered within the space of possible solutions because of the generic and universal character of the rules. However, there is no formalisation of the design problem to be solved, which can consequently result in a somewhat ineffective application of the rules. 
(c) Rules of the art of engineering

These rules come from objective engineering knowledge and are linked to what is commonly called the engineering sciences: mechanical, thermal, fluid mechanics, electricity, magnetism, etc.

These rules integrate various professional practices in several specialty trades, standards used, as well as research and knowledge acquired in our laboratory. We build a knowledge base that allows us to find standard solutions for the design or for solving new technical problems.

For instance, in the mechanical field, if we want to design a rigid mechanical structure, we will move towards components working in traction; if we want a deformable structure, bending will be preferred. Another example would be in directing the mechanical flow by producing structures with rods working in tensile or compressive stress (lattice structure type), where interactions must have a pivot linking behaviour, etc.

\section{(3) Axis 3: Opportunities from change in the energy converter}

The converter in the CTOC method plays an important role in the evolution of the system in question. Indeed, changing the converter implies changing the concept, and if we change the concept we will automatically change the technology or technique used, and therefore the physical phenomena involved are modified.

We propose a physical effects database that allows us to select different effects to change converters that have the same input / output. On the one hand, this enables users to select a new physical effect, which proposes a different converter that will be a new concept, and thus find solutions in other research fields. On the other hand, this base can assist in the physical analysis of the converter in order to find the physical effects involved and relevant physical keywords.

We take into account five input/output energies: thermal, mechanical, chemical, electrical and magnetic. In Figure 7 we show an excerpt from our converter database.

\subsubsection{Innovative solutions}

At this stage, the evolution opportunities encountered turn into innovative solutions from the three evolution axes discussed above. It is then a question of whether to prioritise or hybridise the solutions, that is to say, to use several concepts for the same solution. For any solution found, the method must be reiterated with new keywords.

\section{Application case: biphasic separator}

Currently, according to oil production and reserves, the oil industry needs to exploit previously untapped reserves. Oil processing in offshore platforms at great depths leads oil companies to design complex separation systems. In some offshore oil fields gas/liquid separation is the key. It is indeed essential to separate the gas from the liquid in the sea bottom in order to pump the viscous liquid to the surface. However, beyond 3000 meters deep, voluminous biphasic gravity separators are a big problem and an industrial challenge. Existing systems are based on the principle of decantation, but several constraints must be considered, i.e. residence time, the sporadic production of liquid and gas, sand 


\begin{tabular}{|c|c|c|c|}
\hline Energy (Input) & & Converter/Physical Effect & Energy (Output) \\
\hline \multirow{3}{*}{ Thermal } & $\begin{array}{l}\text { Thermal } \\
\text { expansion }\end{array}$ & $\begin{array}{l}\text { The tendency of matter to change in shape, area, and volume in } \\
\text { response to a change in temperature, through heat transfer. }\end{array}$ & Mechanical \\
\hline & Seebeck effect & $\begin{array}{l}\text { (Thermoelectric effect), A temperature difference between two dissimilar } \\
\text { electrical conductors produces a voltage difference. }\end{array}$ & Electric \\
\hline & Curie Point & $\begin{array}{l}\text { The temperature at which certain materials lose their permanent } \\
\text { magnetic properties, to be replaced by induced magnetism. }\end{array}$ & Magnetic \\
\hline \multirow{3}{*}{ Mechanical } & $\begin{array}{l}\text { Piezoelectric } \\
\text { effect }\end{array}$ & $\begin{array}{l}\text { (Direct), The internal generation of electrical charge resulting from an } \\
\text { applied mechanical force. }\end{array}$ & Electric \\
\hline & Drag (friction) & $\begin{array}{l}\text { The difference in velocities between the fluid threads causes a dissipation } \\
\text { of the mechanical energy which is transformed into heat. }\end{array}$ & Thermal \\
\hline & Villari effect & $\begin{array}{l}\text { [Inverse magnetostrictive effect] The change of the magnetic } \\
\text { susceptibility of a material when subjected to a mechanical stress }\end{array}$ & Magnetic \\
\hline \multirow{4}{*}{ Electric } & Electrostriction & $\begin{array}{l}\text { A property of all electrical non-conductors, or dielectrics, that causes } \\
\text { them to change their shape under the application of an electric field. }\end{array}$ & Mechanical \\
\hline & Peltier effect & $\begin{array}{l}\text { When a current is made to flow through a junction between two } \\
\text { conductors, heat may be generated or removed at the junction. }\end{array}$ & Thermal \\
\hline & Electrolysis & $\begin{array}{l}\text { A method that uses a direct electric current }(D C) \text { to drive an otherwise } \\
\text { non-spontaneous chemical reaction. }\end{array}$ & Chemical \\
\hline & $\begin{array}{l}\text { Magnetoelectric } \\
\text { effect }\end{array}$ & $\begin{array}{l}\text { The phenomenon of inducing magnetic (electric) polarization by applying } \\
\text { an external electric (magnetic) field. }\end{array}$ & Magnetic \\
\hline \multirow{3}{*}{ Magnetic } & Magnetostriction & $\begin{array}{l}\text { A property of ferromagnetic materials that causes them to change their } \\
\text { shape or dimensions during the process of magnetization. }\end{array}$ & Mechanical \\
\hline & Eddy currents & $\begin{array}{l}\text { [Foucault currents] Loops of electrical current induced within conductors } \\
\text { by a changing magnetic field in the conductor. }\end{array}$ & Electric \\
\hline & $\begin{array}{l}\text { Magnetocaloric } \\
\text { effect }\end{array}$ & $\begin{array}{l}\text { A temperature change of a magnetic material subjected to an external } \\
\text { magnetic field. }\end{array}$ & Thermal \\
\hline Chemical & Combustion & $\begin{array}{l}\text { A high-temperature exothermic redox chemical reaction between a fuel } \\
\text { and an oxidant }\end{array}$ & Thermal \\
\hline Fluidic & Venturi effect & $\begin{array}{l}\text { An increase in the speed of a fluid occurs simultaneously with a decrease } \\
\text { in pressure }\end{array}$ & Mechanical \\
\hline Electric & $\begin{array}{l}\text { Electrohydraulic } \\
\text { effect }\end{array}$ & $\begin{array}{l}\text { Intense mechanical shock waves that are produced by underwater } \\
\text { dischargesof store electrical energy. }\end{array}$ & $\begin{array}{l}\text { Mechanical/ } \\
\text { Fluidic }\end{array}$ \\
\hline \multirow{2}{*}{ Radiation } & $\begin{array}{l}\text { Photoelectric } \\
\text { effect }\end{array}$ & $\begin{array}{l}\text { The creation of voltage or electric current in a material upon exposure to } \\
\text { light }\end{array}$ & Electric \\
\hline & $\begin{array}{l}\text { Opto-hydraulic } \\
\text { Effect }\end{array}$ & The direct transformation of solar energy into mechanical vibrations & Mechanical \\
\hline
\end{tabular}

Figure 7. Excerpt from database of energy converters.

management, etc. There is an extensive literature on the design of biphasic separators for use upstream of multiphase pumps, nevertheless, a large number of patents and scientific articles on the subject state that no separator has yet achieved a satisfactory performance (Tor, Torbjoern, and Bjoernar 2012).

\subsection{Application of the first stage: problem definition}

The oil and gas produced from wells in producing fields form a biphasic mixture. This gas either comes from the solution (fluid) when the pressure decreases as the mixture flows from the reservoir to the facilities (separator), or is already present in the form of free gas at the same pressure and temperature as the reservoir. If the pressure in the oil is not sufficient to lift the extracted fluid to the surface with an established flow rate, the extraction wells are equipped with an artificial lifting method.

\section{(1) Problem's main function}

It is essential to separate the gas phase from the liquid phase because of various problems:

- The gas produced by the wells reduces the oil flow capacity in the biphasic lines and the volumetric pumping efficiency is thus reduced. 
- The variable flow regime can result in a transient state that intermittently impacts pipelines and equipment.

- The sand and solids mixed in the biphasic mixture should be managed.

- The pressure drop should be minimised to improve biphasic separation.

We are therefore looking for concepts to perform the function of 'separating oil from gas' or 'separating gas from oil'; these are the main functions of this study.

(2) Main constraints involved

- The formation of hydrates or crystallised salts,

- Thermal fluids (avoid cooling the liquid in order to prevent hydrate formation and no process allowed less than $20^{\circ} \mathrm{C}$ and above 20 bar),

- Sand management (Solid/liquid separation),

- Management of the environmental factors (i.e. withstand corrosion and free maintenance),

- Slug management (sporadic production of liquid and gas). Avoid blockages that can cause unstable conditions and handling problems for downstream installations.

(3) Life stages, external environments and available resources

The Life Stages (LS) are:

LS1. The separation system has no biphasic mixture in its input.

LS2. The biphasic separation starts when the mixture hits the bottom of the container (separator).

LS3. The inlet flow is stopped but the system continues to separate the mixture stored by residence time.

LS4. The separation system is drained; the separation process is then finished.

In all life stages we find the following external environments: oil, gas, sea water (ocean), reservoir (oil well, rocks, etc.). Notably, we are looking to improve the performance in the relevant life stages (LS2 and LS3 in our case).

Concerning the available resources, we take into account the twelve classes defined by Samet (2010) from the work of Savransky (2000). These classes are: substances, energies, information, space, time, functional resources, self-service, interaction resources, organisational resources, differential resources, earlier resources, waste. Citing a few examples, we have:

- Substances: Biphasic mixture (gas, sand, brine, liquid), sea water, the sea bottom, separation facilities, marine nature, etc.

- Energies: Thermal, chemical, kinetics, tidal power, etc.

- Information: Temperature, pressure, vibrations.

- Space: During installation, prior to operation, during operation (separation), during maintenance periods.

- Functional resources: Deformability of the parts, inertial effects.

- Self-service: Geometrical, physical, and chemical properties.

- Differential resources: Temperature gradients (Gas, Liquid), pressure gradients, chemical potential gradient. 
Main Function: Gas liquid separation system for deep offshore

\begin{tabular}{|l|l|}
\hline \multicolumn{1}{|c|}{ QUERIES } \\
\hline $\mathbf{1}$ & Liquid gas separator \\
\hline $\mathbf{2}$ & Gas liquid separator \\
\hline $\mathbf{3}$ & Oil gas separator \\
\hline 4 & Gas oil separator \\
\hline $\mathbf{5}$ & Liquid gas system separator \\
\hline $\mathbf{6}$ & Biphasic separator \\
\hline $\mathbf{7}$ & Sand management separator \\
\hline $\mathbf{8}$ & Slug biphasic separator \\
\hline $\mathbf{9}$ & Hydrates management separator \\
\hline $\mathbf{1 0}$ & TOTAL separator \\
\hline $\mathbf{1 1}$ & FMC separator \\
\hline $\mathbf{1 2}$ & Deep offshore separator \\
\hline $\mathbf{1 3}$ & Pazflor separator system \\
\hline $\mathbf{1 4}$ & Offshore separator \\
\hline $\mathbf{1 5}$ & Petroleum separator \\
\hline$\ldots .$. & ............................................. \\
\hline
\end{tabular}

Figure 8. Examples of queries used in the definition stage.

- Waste: Thermal losses.

- ...

These resources give us an overview of the problem addressed and a fine perception of the problem environment.

(4) Searching for what exists

Figure 8 shows an example of some queries used to start the search. The aim of this section is to have an overview of existing technologies, physical phenomena involved, and any relevant concept related to the main function.

We find new concepts, specific terms of the oil language, and several proposed solutions for each constraint listed above. We built the first element of the biphasic separator knowledge base. Furthermore, several technological systems are identified, i.e. cyclones, hydro-cyclones, blades, plates, helices ... Our goal now is to further develop these systems. To perform the main function, we must then find components linked to the movement of the functional flow. For example, in liquid/gas separation, the final goal will be to define all physical phenomena to produce a force (F), which will displace (with velocity V) droplets independently of the gas flow. This analysis will be performed in the next stage.

\subsection{Application of the second stage: research and analysis}

In this stage, we exploit the keyword database by generating different queries such as: 'gas; liquid; separator (device, apparatus, system, process, method, etc.)'. At one point, this kind of query yields nothing more than what the same technological systems have already found 

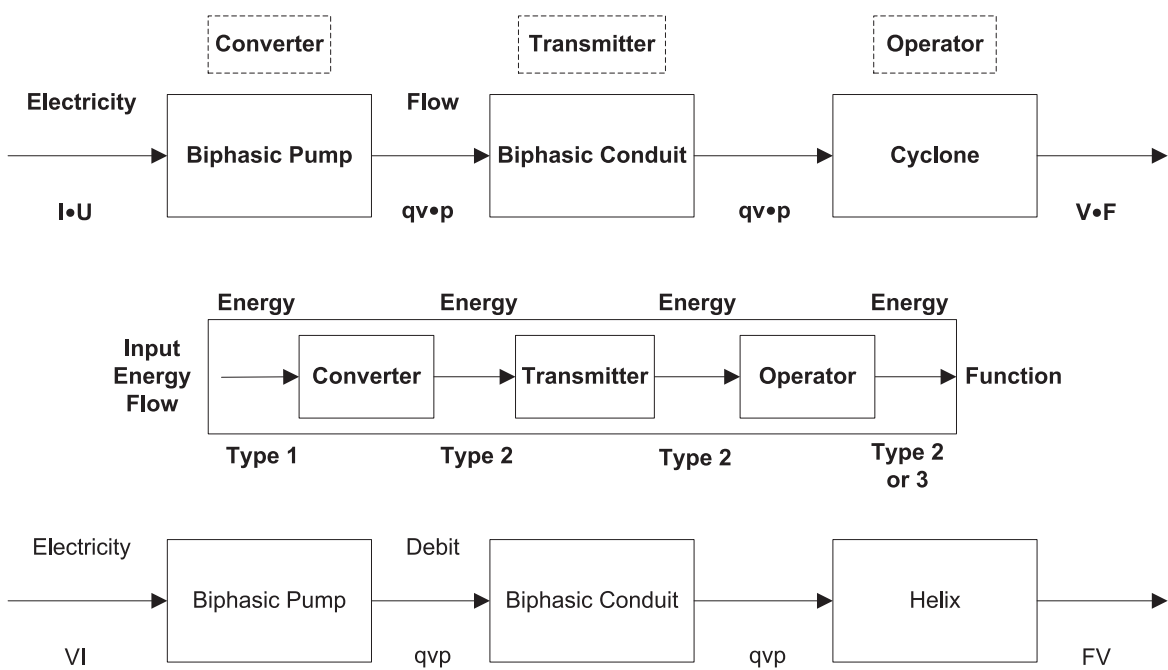

Figure 9. Decomposition of a system applied to a biphasic separator.

(i.e. settling tanks, propellers, cyclones, etc.) (Figure 8). It is thus necessary to improve the relevance of the keyword database by completing it with pertinent physical keywords.

To perform the main function, it is appropriate to define the components related to the circulation of the functional flow. In order to illustrate this point, consider the liquid/gas separation case, when the gas flow is greatest and the oil is in the form of droplets.

If we consider the example of separation by centrifugal force, several concepts are known: cyclones, helices, blades, etc. We will focus on and start our example with cyclones. Available energy (input) is electrical energy. The classic converter that can convert electrical energy into fluid energy is a biphasic pump. The biphasic conduit is the transmitter. Finally, the operator is the element that will help transform the fluid power ( $q v \cdot p)$ into radial displacement of droplets $(\mathrm{V} \cdot \mathrm{F})$, which is the role of the cyclone (Figure 9). The cyclone is also a converter, and will be explored for possible future evolutions.

In the operator, the biphasic flow has a circular motion and the liquid droplet undergoes a centrifugal force, which moves it towards the periphery where it is recovered (Figure 10).

The fundamental principle of dynamics (law of conservation of momentum) is written here for a droplet:

$$
\sum \vec{F}=m \cdot \frac{V^{2}}{R} \vec{i}+m \frac{d V \vec{j}}{d t}
$$

$\sum F$ includes the friction of the liquid/gas contact with the cyclone and the weight. In order to visualise the relevant parameters, we express the mass $\boldsymbol{m}$ of the droplet as a function of the diameter $\boldsymbol{d}$ and the density $\rho$ :

$$
\sum \vec{F}=\frac{1}{6} \rho \pi d^{3} \frac{V^{2}}{R} \cdot \vec{i}+\frac{1}{6} \rho \pi d^{3} \frac{d V}{d t} \cdot \vec{j}
$$

Two parameters from the centrifugal force are relevant: the velocity $(\mathbf{V})$ and the diameter (d) of the droplet. If we want to increase the centrifugal force, we can manipulate these two parameters. For instance, if we want to increase the diameter of the droplets, we might 


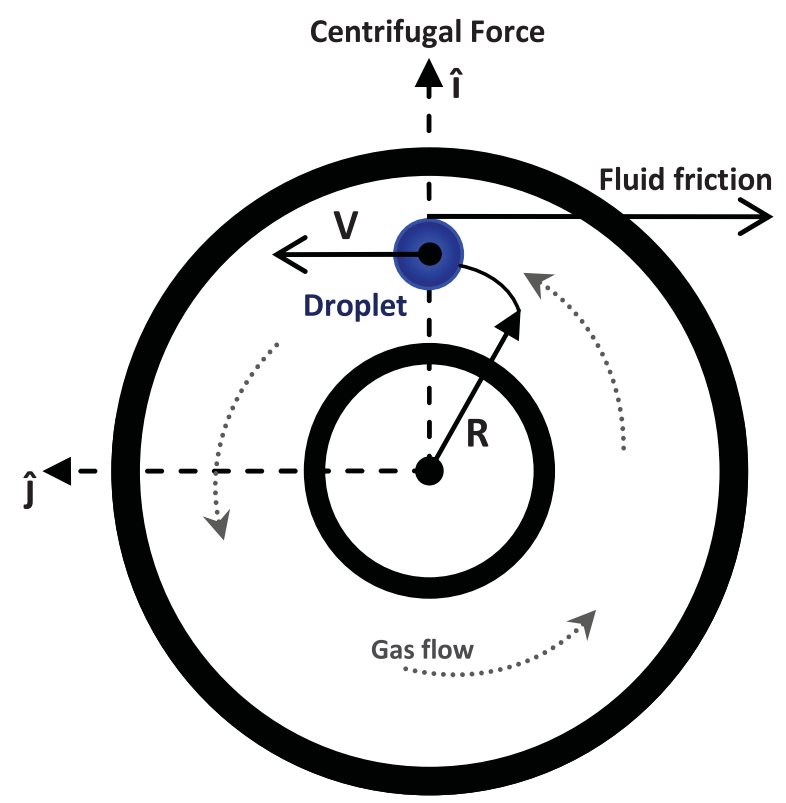

Figure 10. Biphasic separation concept by centrifugation.

intuitively think of the notion of droplet reunion or something that refers to the idea of reunification. Using the WordNet semantic dictionary (Fellbaum 1998), we found different interpretations (senses) of the word 'reunion'. Two interpretations were found; particularly the second states that 'the union of diverse things into one body or form or group', or 'the growing together of parts'. In this category we find different keywords such as coalescence, coalescency, coalition, concretion, conglutination, etc. We can then infer that the coalescence of droplets carried by the approximation, vibration, or collision of fusion droplets increases the diameter. This brief analysis gives us the physical keywords centrifugation (increase of the centrifugal force) and coalescence (increase of the diameter of the droplet), and we can then deduce the improvement techniques of approximation, collision and vibration.

These keywords represent key elements that will be added to the keyword database, and then a new search for concepts can be performed. It is possible and appropriate to perform a functional decomposition and the associated physical analysis of the other technological systems that have been found. It is not within the scope of this article to demonstrate each CTOC analysis.

Through several iterations of research and analysis, our knowledge base has now increased. We have integrated all pertinent keywords hitherto recovered, i.e. initial keywords, techniques found (technological systems), physical keywords, etc. Figure 11 illustrates this database, which can still be used to search for new concepts.

Using the knowledge base, we can enrich or expand the initial keywords, and in particular, we can get to relevant patents (or interesting concepts) only by reducing the number of patents found (which also decreases the number of patents to be analyzed).

For instance, an initial search with the keywords 'gas, liquid, separator' yields 19435 patents. It is obvious that without the proper tools, manual analysis of these documents is 


\begin{tabular}{|c|c|c|c|c|c|c|c|c|c|c|}
\hline Noun (Nn) & \begin{tabular}{|l}
\multicolumn{1}{|c|}{ PETROLEUM } \\
crude oil \\
crude \\
rock oil \\
fossil oil \\
fossil fuel \\
oil
\end{tabular} & $\begin{array}{l}\text { LIQUID(s) } \\
\text { fluid (s) } \\
\text { incopressible fluid }\end{array}$ & $\begin{array}{l}\quad \text { GAS } \\
\text { gaseous } \\
\text { gasoline } \\
\text { gasolene } \\
\text { petrol } \\
\text { fuel } \\
\text { petrol } \\
\end{array}$ & $\begin{array}{l}\text { HYDROCARBON(S) } \\
\text { organic compound } \\
\text { hydrogen-carbon }\end{array}$ & \begin{tabular}{l}
\multicolumn{1}{c}{ MIXTURE } \\
mix \\
conglomeration \\
conglobation \\
combination
\end{tabular} & $\begin{array}{l}\text { MULTI-PHASE } \\
\text { polyphase } \\
\text { three-phase } \\
\text { two-phase } \\
\text { bihhasic } \\
\text { diphasic }\end{array}$ & \begin{tabular}{l}
\multicolumn{1}{c}{ SLUG(S) } \\
stagnate \\
slugging \\
slug flow \\
plugs
\end{tabular} & \begin{tabular}{l}
\multicolumn{1}{c}{ FLOW } \\
stream \\
flow rate \\
flux \\
motion \\
displacement \\
translation
\end{tabular} & $\begin{array}{l}\text { WATER } \\
\text { H2O } \\
\text { liquid } \\
\text { binary compound } \\
\text { chemical substance }\end{array}$ & \begin{tabular}{l}
\multicolumn{1}{c}{ SAND } \\
soil \\
dirt \\
granular material
\end{tabular} \\
\hline [Category 1] & \begin{tabular}{|l} 
BUBBLE \\
globule of gas \\
globule
\end{tabular} & \begin{tabular}{l}
\multicolumn{1}{c}{ DROP } \\
drib \\
dribletf \\
bead \\
pearl \\
droplet
\end{tabular} & $\begin{array}{l}\text { FOAM } \\
\text { foaming } \\
\text { roth } \\
\text { fizz } \\
\text { effervesce } \\
\text { spumous } \\
\text { bubbling } \\
\end{array}$ & \begin{tabular}{l}
\multicolumn{1}{c}{ EMULSION(S) } \\
colloid \\
substance \\
mixture
\end{tabular} & $\begin{array}{l}\text { ENTRY } \\
\text { inlet } \\
\text { entrance } \\
\text { access } \\
\text { arrival }\end{array}$ & & & & & \\
\hline $\begin{array}{c}\text { Verb / } \\
\text { Adjective (Vn) } \\
\text { [Category 2] }\end{array}$ & \begin{tabular}{|l}
\multicolumn{1}{|c}{ SEPARATE } \\
separating \\
separation \\
divide \\
split
\end{tabular} & \begin{tabular}{l}
\multicolumn{1}{c}{ STRATIFY } \\
stratifying \\
distinguish \\
secern \\
tell apart
\end{tabular} & \begin{tabular}{l}
\multicolumn{1}{c}{ USE } \\
utilize \\
utilise \\
apply \\
employ \\
apply
\end{tabular} & \begin{tabular}{l}
\multicolumn{1}{c}{ DEGASIFIER(S) } \\
degasser \\
degasification
\end{tabular} & $\begin{array}{l}\text { RECOVERER } \\
\text { recuperation } \\
\text { recovery } \\
\text { retrieval }\end{array}$ & \begin{tabular}{l}
\multicolumn{1}{c}{ ROTARY } \\
rotation \\
gyration \\
turning \\
turn \\
cyclical \\
\end{tabular} & \begin{tabular}{l}
\multicolumn{1}{c}{ ENHANCED } \\
enhance \\
better \\
improuve \\
ameliorate \\
upgrade
\end{tabular} & $\begin{array}{l}\text { TREAT } \\
\text { treating } \\
\text { process }\end{array}$ & \begin{tabular}{l}
\multicolumn{1}{c}{ COMPRISE } \\
comprising \\
consist \\
contain \\
incorporate \\
constitute
\end{tabular} & \begin{tabular}{l}
\multicolumn{1}{c}{ CONTROL } \\
controlling \\
operate \\
manipulate
\end{tabular} \\
\hline \multirow{3}{*}{$\begin{array}{c}\text { Physical } \\
\text { Phenomena } \\
\text { (PPn) } \\
\text { [Category 3] }\end{array}$} & 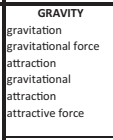 & $\begin{array}{l}\text { CENTRIFUGAL } \\
\text { centripetal } \\
\text { inertial force } \\
\text { fictitious } \\
\text { centrifugation }\end{array}$ & $\begin{array}{l}\text { SHOCK } \\
\text { impact } \\
\text { collision } \\
\text { hit } \\
\text { contact } \\
\text { impinging }\end{array}$ & \begin{tabular}{l}
\multicolumn{1}{c}{ COALESCENCE } \\
coalescency \\
coalition \\
concretion \\
conglutination \\
reunion \\
approximation \\
merging \\
\end{tabular} & $\begin{array}{l}\text { FAll } \\
\text { drop } \\
\text { descent } \\
\text { gravitation }\end{array}$ & $\begin{array}{l}\text { RESIDENCE TIME } \\
\text { duration } \\
\text { continuance } \\
\text { span }\end{array}$ & $\begin{array}{l}\text { VORTEX } \\
\text { whirl } \\
\text { swirl } \\
\text { convolution } \\
\text { whirlpool } \\
\text { maelstrom } \\
\text { twirl }\end{array}$ & $\begin{array}{l}\text { INERTIA } \\
\text { inertial } \\
\text { iners } \\
\text { sluggish }\end{array}$ & $\begin{array}{l}\quad \text { VIBRATION } \\
\text { oscillation (s) } \\
\text { shaking } \\
\text { undulation } \\
\text { wave } \\
\text { resonance } \\
\text { brandishing }\end{array}$ & \begin{tabular}{l}
\multicolumn{1}{c}{ ROTATION } \\
rotary motion \\
revolution \\
gyration \\
turning \\
turn \\
circular movement
\end{tabular} \\
\hline & \begin{tabular}{|l}
\multicolumn{1}{|c|}{ DENSITY } \\
compactness \\
denseness \\
concentration \\
volumetric mass
\end{tabular} & $\begin{array}{l}\text { INCUNATION } \\
\text { inclining } \\
\text { tilt } \\
\text { lean } \\
\text { leaning }\end{array}$ & $\begin{array}{l}\text { DYNAMIC } \\
\text { dynamical } \\
\text { dynamis } \\
\text { powerful }\end{array}$ & $\begin{array}{l}\text { ELECTROSTATIC } \\
\text { static } \\
\text { electrostatics } \\
\text { electric charges } \\
\text { static electricity }\end{array}$ & $\begin{array}{l}\text { FLOTATION } \\
\text { floatation } \\
\text { buoyancy }\end{array}$ & $\begin{array}{l}\text { SEDIMENTATION } \\
\text { depositt } \\
\text { alluviation } \\
\text { settle }\end{array}$ & $\begin{array}{l}\text { DECANTATION } \\
\text { ransfussion } \\
\text { decant }\end{array}$ & $\begin{array}{l}\quad \text { COHESION } \\
\text { union } \\
\text { unification } \\
\text { connection } \\
\text { link } \\
\text { cohesive }\end{array}$ & $\begin{array}{l}\text { DECOHESION } \\
\text { disunion }\end{array}$ & \begin{tabular}{l}
\multicolumn{1}{c}{ ACCELERATION } \\
change \\
alteration \\
speeding \\
rate
\end{tabular} \\
\hline & \begin{tabular}{|l}
\multicolumn{1}{|c}{ AMPLITUDE } \\
shifftrequence \\
displacement \\
periodic variable
\end{tabular} & $\begin{array}{l}\text { FREQUENCY } \\
\text { undynamic } \\
\text { occurrences }\end{array}$ & \begin{tabular}{l}
\multicolumn{1}{|c|}{ STATIC } \\
adynamic \\
inactive \\
motionless \\
still \\
unchanging \\
\end{tabular} & & & & & & & \\
\hline \multirow{2}{*}{$\begin{array}{l}\text { Technological } \\
\text { Systems (Tn) } \\
\text { [Category 4] }\end{array}$} & \begin{tabular}{|c|} 
CYCLONE(S) \\
cyclonic separation \\
removing particles
\end{tabular} & $\begin{array}{c}\text { PLATE(S) } \\
\text { baffle (s) }\end{array}$ & $\begin{array}{l}\text { VANE(S) } \\
\text { blade (s) } \\
\text { fin (s) }\end{array}$ & $\begin{array}{l}\text { HYDROCYCLONE(S) } \\
\text { cyclone (s) }\end{array}$ & $\begin{array}{l}\text { TUBE (S) } \\
\text { tubing } \\
\text { conduit } \\
\text { pipe } \\
\text { duct }\end{array}$ & $\begin{array}{l}\text { TRAY (S) } \\
\text { receptacle }\end{array}$ & $\begin{array}{l}\text { PIPELINE(S) } \\
\text { line } \\
\text { pipe } \\
\text { pipage } \\
\text { piping } \\
\text { manifold } \\
\text { riser }\end{array}$ & \begin{tabular}{l}
\multicolumn{1}{c}{ TANK } \\
vessel \\
storage tank \\
container \\
reservoir
\end{tabular} & $\begin{array}{l}\text { HELIX } \\
\text { coil } \\
\text { spiral } \\
\text { volute } \\
\text { whorl } \\
\text { curved shape } \\
\text { helices }\end{array}$ & $\begin{array}{l}\text { DEMULIIFIER(S) } \\
\text { emulsion breakers } \\
\text { separate emulsions } \\
\text { specialty chemicals }\end{array}$ \\
\hline & \begin{tabular}{|l}
\multicolumn{1}{|c|}{ CONDENSER } \\
extractor \\
heat pump \\
purifier \\
submersible \\
coil \\
condense \\
\end{tabular} & $\begin{array}{l}\text { COALESCER } \\
\text { separate } \\
\text { emulsions } \\
\text { performing } \\
\text { coalescence }\end{array}$ & \begin{tabular}{l}
\multicolumn{1}{c}{ PILE } \\
agglomerate \\
cumulation \\
cumulus \\
collection \\
aggregation \\
assemblage
\end{tabular} & $\begin{array}{l}\text { SLUG CATCHER } \\
\text { vessel type } \\
\text { finger type } \\
\text { parking loop }\end{array}$ & $\begin{array}{l}\text { DEFLECTOR(S) } \\
\text { agglomerator } \\
\text { bubbler } \\
\text { heat exchanger }\end{array}$ & SATELITE & $\begin{array}{l}\text { CHEMICAL AGENT } \\
\text { agent } \\
\text { eliminator } \\
\text { substance }\end{array}$ & & & \\
\hline $\begin{array}{l}\text { Type (Singular } \\
\text { / Plural) } \\
\text { [Category 5] }\end{array}$ & \begin{tabular}{|c} 
METHOD(S) \\
know-how \\
knowledge
\end{tabular} & \begin{tabular}{l}
\multicolumn{1}{c}{ PROCESS } \\
procedure \\
activity \\
operation
\end{tabular} & $\begin{array}{l}\text { DEVICE } \\
\text { equipment } \\
\text { system (s) } \\
\text { medium } \\
\text { machine }\end{array}$ & $\begin{array}{l}\quad \text { SEPARATOR(S) } \\
\text { apparatus } \\
\text { setup } \\
\text { centrifuge } \\
\text { ultracentrifuge }\end{array}$ & \begin{tabular}{l}
\multicolumn{1}{c}{ ARTIFACT(S) } \\
artefact \\
item \\
unit (s) \\
component \\
part \\
portion
\end{tabular} & $\begin{array}{l}\text { TYind } \\
\text { TYPE(S) } \\
\text { sort } \\
\text { form } \\
\text { variety } \\
\text { block } \\
\text { taxonomy }\end{array}$ & $\begin{array}{l}\text { CHAMBER(S) } \\
\text { enclosure } \\
\text { cavity } \\
\text { bodily } \\
\text { room } \\
\text { assembly }\end{array}$ & $\begin{array}{ll} & \text { AXIAL } \\
\text { axis } & \end{array}$ & \begin{tabular}{l}
\multicolumn{1}{c}{ ORIENTATION } \\
horizontal \\
vertical \\
placement \\
juxtaposition \\
superposition
\end{tabular} & $\begin{array}{l}\text { PRODUCTION } \\
\text { product } \\
\text { creation } \\
\text { activity }\end{array}$ \\
\hline \multirow{2}{*}{$\begin{array}{c}\text { Company / } \\
\text { Country } \\
\text { [Category 6] }\end{array}$} & $\begin{array}{l}\text { PHILPS PETROLEUM } \\
\text { JuLS. } \\
\text { American }\end{array}$ & $\begin{array}{l}\text { SHELL } \\
\text { United Kingdom } \\
\text { Netherlands } \\
\text { Anglo-Dutch }\end{array}$ & \begin{tabular}{l}
\multicolumn{1}{c}{ PEMEX } \\
Mexican \\
Mexico
\end{tabular} & $\begin{array}{l}\text { BRITISH PETROLEUM } \\
\text { BP P.L.C } \\
\text { England }\end{array}$ & $\begin{array}{l}\text { CANADIAN OIL } \\
\text { Canadian } \\
\text { Canada }\end{array}$ & $\begin{array}{l}\text { ESSO RESEARCH } \\
\text { American } \\
\text { U.S. }\end{array}$ & $\begin{array}{l}\quad \text { PETROBRAS } \\
\text { Brazil } \\
\text { Brazilian }\end{array}$ & $\begin{array}{c}\text { MOBILOIL } \\
\text { CORPORATION } \\
\text { ExxonMobil } \\
\text { American }\end{array}$ & $\begin{array}{l}\text { BEDING BRIGHT } \\
\text { PETROLEUM } \\
\text { China } \\
\text { Asia }\end{array}$ & $\begin{array}{l}\text { CHIINA NAT } \\
\text { OFFSHORE OIL CORP } \\
\text { Chinese } \\
\text { China }\end{array}$ \\
\hline & \begin{tabular}{|c} 
CHEVRON \\
CORPORATION \\
American \\
u.S.
\end{tabular} & $\begin{array}{l}\text { TOTAL } \\
\text { France } \\
\text { French }\end{array}$ & \begin{tabular}{l}
\multicolumn{1}{c}{ EXXON } \\
United States \\
American
\end{tabular} & $\begin{array}{l}\text { FMC CORPORATION } \\
\text { FMC } \\
\text { United States } \\
\text { U.S. }\end{array}$ & $\begin{array}{l}\text { CHINA PETROLEUM } \\
\text { China } \\
\text { Chinese }\end{array}$ & $\begin{array}{l}\text { BEIING OIL HBP } \\
\text { SCIENCE } \\
\text { China } \\
\text { HBP Group }\end{array}$ & & & & \\
\hline $\begin{array}{l}\text { Complement } \\
\text { [Category 7] }\end{array}$ & $\begin{array}{l}\text { OFFSHORE } \\
\text { sea } \\
\text { offshore plattorm }\end{array}$ & $\begin{array}{l}\quad \text { ONSHORE } \\
\text { inshore } \\
\text { seaward } \\
\text { land }\end{array}$ & $\begin{array}{l}\text { WELL } \\
\text { excavation } \\
\text { vessel } \\
\text { source }\end{array}$ & $\begin{array}{l}\quad \text { UNDERWATER } \\
\text { submerged } \\
\text { submersed } \\
\text { subsurface } \\
\text { subaqueous } \\
\text { subaquatic }\end{array}$ & \begin{tabular}{l}
\multicolumn{1}{c}{ DEEP } \\
deep-water \\
oceanic abyss \\
profound \\
deep-well \\
abysmal
\end{tabular} & $\begin{array}{l}\text { SUBSEA } \\
\text { fully submerged } \\
\text { deep ocean } \\
\text { seabed }\end{array}$ & $\begin{array}{l}\text { PLATFORM } \\
\text { surface } \\
\text { level } \\
\text { flat surface }\end{array}$ & & & \\
\hline
\end{tabular}

Figure 11. Excerpt from the keyword database for biphasic separator systems.

an impossible task; even analyzing just a few documents remains a time-consuming activity. If we want to narrow the search using the logic of the converters, we include the word 'cyclone', we now have 1052 patents.

To focus the search, we use the new keywords found by means of the functional decomposition, then the search is launched again. Figure 12 shows the step-by-step process.

Five results are found, containing the keywords 'gas; liquid; coalescence; cyclone; separator'. In particular, patent CN202052637 uses a hybrid technique of centrifugation and gravity chute to separate liquid droplets from the gas stream. We notice that the words 'gravity and collision' in our database were not used and only the words 'coalescence and cyclone' were needed to find them.

Take, for instance, the fifth patent (US4154972). This was not found among the 1052 patents that include the keyword cyclone (due to search engine database). The concept is hybrid, a cyclone, and a high voltage electrode to promote coalescence. 


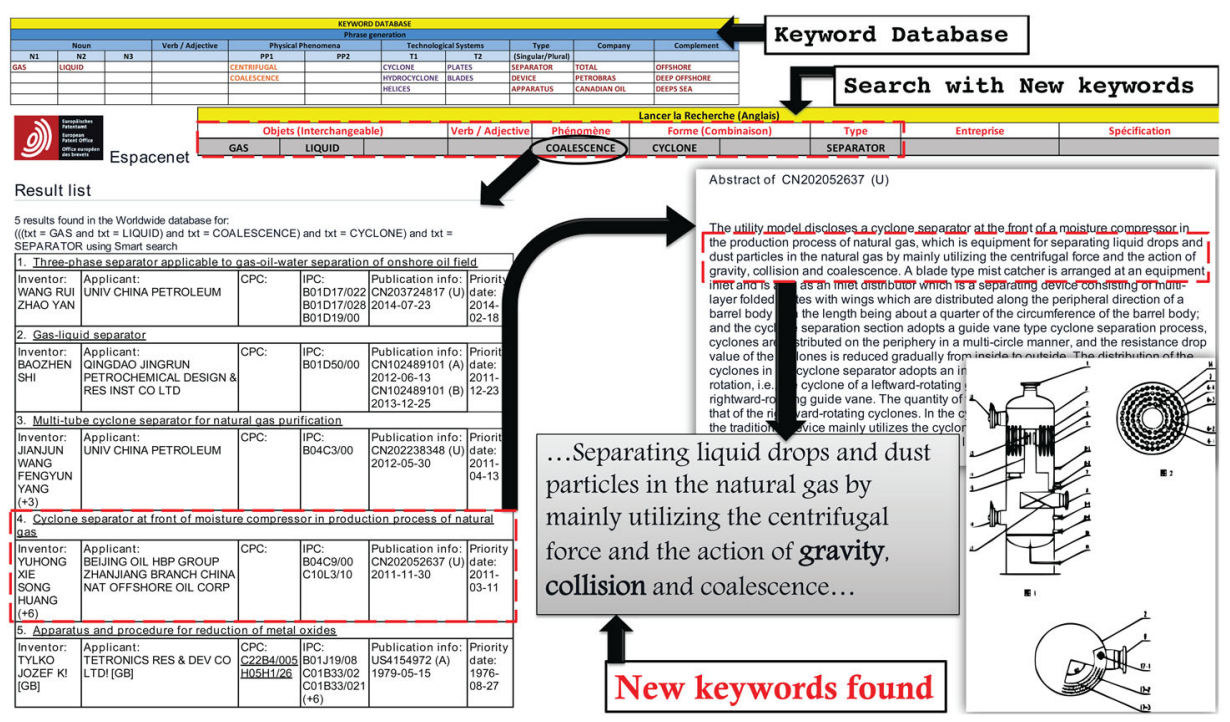

Figure 12. Application example, research by exploiting new keywords.

A new search is performed with three words: 'gas, liquid, coalescence' (which leads to 213 patents). In this case we note, for example, that the nineteenth patent (CN2026666475) uses high resonant frequency to achieve coalescence. So it becomes clear that keyword coalescence has led us to new fields of research, thus demonstrating the value of the method.

At this point, by means of several iterations, we have enough elements to structure a discovery matrix crossing the physical phenomena found with the technological systems recovered.

More than 200 patents were analyzed; 50 were considered relevant and were classified in the discovery matrix. Information related to each patent (description, year, company, etc.) was automatically recovered from a reading grid which is accessible from the matrix. A colour code indicates a second degree of internal patent pertinence (useful, might be useful, and not useful). This second degree of pertinence was defined by several criteria in relation to the previously mentioned constraints. For example, in the knowledge recovery phase some patents were considered relevant from the summary. The physical phenomena and related techniques selected are then used in the discovery matrix to classify the patent. In a second analysis, some patents will be confronted with various constraints, in this casestudy, slug, hydrates, sand management, etc. This second filter will detach the most relevant patents in the context of the current study.

\subsection{Application of the third stage: innovation, opportunities and solutions}

\subsubsection{Analysis of the discovery matrix}

Different types of biphasic separation were found among the analyzed patents, i.e. liquid/gas, gas/liquid, liquid/liquid, liquid/solid, etc. The principal technologies found relate to: helices, cyclones, hydro-cyclones, trays, baffles, T-junction, tanks, containers, etc. Many physical phenomena are identified: Archimedes, drop, collision, coalescence, diffusion, 
thermal gradient, etc. For instance, in Figure 13 we have one discovery matrix that displays some pertinent patents concerning the case of predominantly gas stream. By simple observation, we notice well-defined trends toward the use of tray systems, baffles, deflectors; they are related to the use of collisions and drops. Several cyclone systems have been identified by the physical phenomenon of centrifugal force; a stop point has been identified for this duo (PP \& T).

Because of the repetition of the results, several cyclone patents are no longer classified. Very few patents have been found for helices and T-junction technologies. Note that the keywords 'helices' and 'coalescence' do not give results (empty cell). In any case, it is advisable to explore possible solutions in this area. The other empty cells are concepts that are either non-existent or not found; innovative work is, therefore, foreseeable.

In observing and analyzing all the discovery matrices, first tracks emerge (in this article, we only illustrate the $\mathrm{G} / \mathrm{L}$ case). It is pertinent to show the patents ordered by their release date (timeline classification). This classification shows the different technology changes that biphasic separation systems have undergone. In order to identify the first evolution opportunities, a more structured analysis with the evolution trends must be performed.

\subsubsection{In search of evolution opportunities - implementation of the three axes}

(1) Application example of Axis 1: Empty cells

An analysis of the matrix empty cells (Figure 14) reveals that no patent has been found by linking the physical phenomenon of coalescence with techniques such as electrodes, Tjunctions, chemical agents, etc. As we have already seen, there may be several reasons: The research is not exhaustive, or the concept is in the public domain, or the concept has not been patented, etc. but in any case we can analyze empty cells in a more detailed way.

Some of the main findings are:

- Combination with a heat exchanger which streamlines liquids is an interesting track. Indeed, heating is very interesting because it will prevent the formation of hydrate plugs.

- The coalescence phenomenon realised specifically by T-junction technologies is not used. This non-patented concept is therefore a track to study because, a priori, there is no technology lock-in.

- The coalescence/electrodes duo still produces pertinent patents using keywords from our database 'gas; liquid; coalescence; electrodes', the search yields 3 patents. Patent US4154972 is a hybrid concept composed of a cyclone and high-voltage electrodes to promote coalescence. This patent is now considered relevant and classified in the matrix.

- Finally, we perform a new search with the keywords 'gas, liquid, coalescence, chemical agent', and find only two patents. The second concerns the field of synthetic polymers, where the coalescence of the water insoluble particles is done by the use of solvents (GB767015). In subsequent analyses, we found some inventions that used chemical coalescing agents (polymers) better known as 'demulsifiers' in the context of oil/water separation (US2011042288). We then have more elements for new searches by including the keywords 'chemical agent', and 'demulsifier'.

This iterative procedure allows us to complete the matrix, to validate concepts not found and to arrive at the first evolution opportunities. 


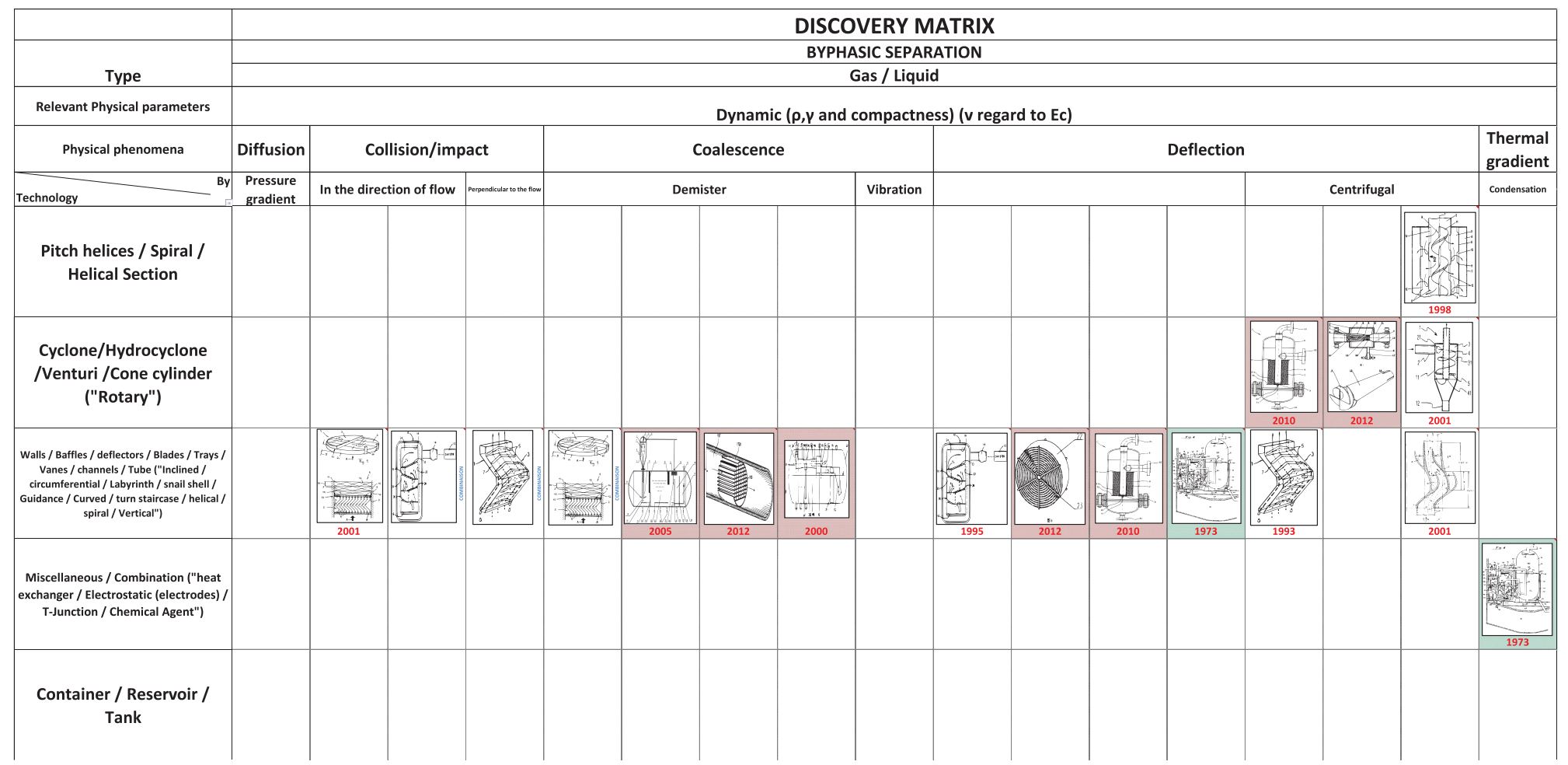

Figure 13. Discovery matrix of biphasic separators (predominantly gas stream) (Green - useful, orange - might be useful, red - not useful, white - not defined). 


\begin{tabular}{|c|c|c|}
\hline & \multicolumn{2}{|c|}{ DISCOVERY MATRIX } \\
\hline & \multicolumn{2}{|c|}{ BYPHASIC SEPARATION } \\
\hline Type & \multicolumn{2}{|c|}{ Gas / Liquid } \\
\hline Relevant Physical parameters & \multicolumn{2}{|c|}{ Dynamic ( $\rho, \gamma$ and compactness) ( $v$ regard to $E c)$} \\
\hline Physical phenomena & \multicolumn{2}{|c|}{ Coalescence } \\
\hline Technology & Demister & Vibration \\
\hline \multicolumn{3}{|l|}{ Heat Exchanger } \\
\hline \multicolumn{3}{|l|}{ T-Junction } \\
\hline \multicolumn{3}{|l|}{ Electrodes } \\
\hline Chemical Agent & & \\
\hline
\end{tabular}

Figure 14. Example of the discovery matrix empty cells.

(2) Application example of Axis 2: Patent timeline and evolution trends

In this second axis, we analyze the discovery matrixes (ordered in timeline) through an evolutionary perspective (see Section 3.3.2). The families or technological branches of selected biphasic separators evolve over time (R4), i.e. the shape (R1), the arrangement of components (R2), materials (R6), etc. These evolutions are analyzed and compared with the evolution trends (evolution laws and rules). For example, an evolution trend analysis is performed for helix systems (Figure 15) followed by an analysis for tray systems (including deflectors, fins, baffles, etc.) (Figure 16).

Patents that performed biphasic separation by helical means in the period 1978-2006, showed evolution trends such as: coordination of rhythms (L3, helices are in phase or in phase opposition), increase in the degree of perfection (L4, increase in the complexity of the separator) and transition to external environments (L6, evolving towards bi-poly-systems).

They unveiled an evolution from one helix to several helices (L6, identical poly-systems and L4, segmentation trends), fluid recovery at the sides and then at the bottom. In 2006 in particular, variable pitch inverted helices illustrated the dynamisation (L4, L8) of components and the change of rhythm (L3).

Relevant classified patents that used trays or plates during the short span between 1984 and 1996 already show identical systems and segmentation principles (L4, divided into several entities) at the beginning of this period, followed by an evolution in shape (R1) and the addition of different systems (R7). Especially in 1996, we find a system that manifests an evolution towards poly-systems (L6, union of several identical or similar mono-systems) and has integrated systems with inverse or opposite functions (R5), i.e. the integration of the inverted plate to ensure biphasic separation, and particularly interesting for slug management, concerning the aforementioned constraint.

We can deduce that patents analyzed by evolution trends give some suggestions for possible areas of innovation. The possibility of analyzing multiple technologies by trends provides further inspiration as we move toward hybrid systems that integrate several concepts for achieving the desired function. 


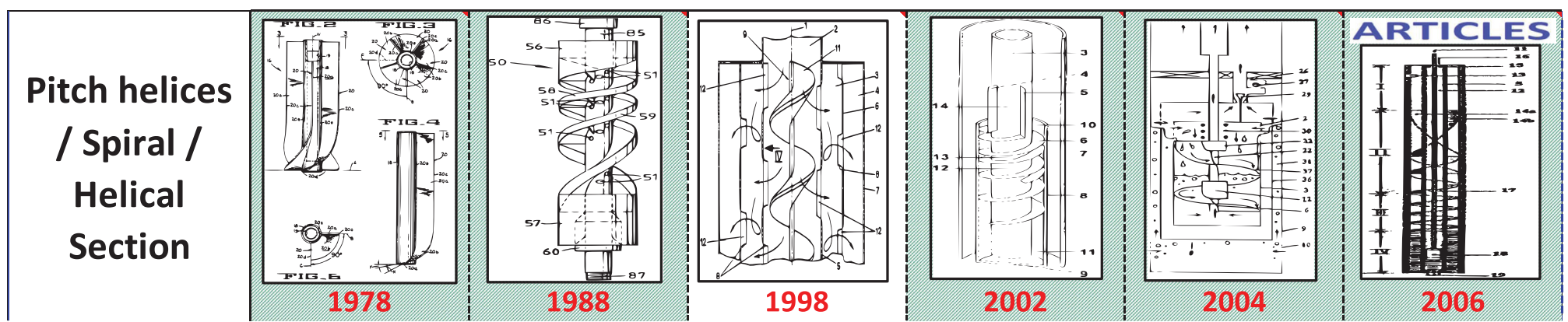

Figure 15. Excerpt from the timeline of patents that contain helix elements. 


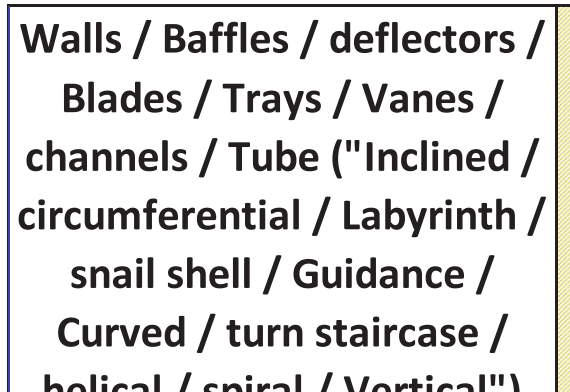

helical / spiral / Vertical")
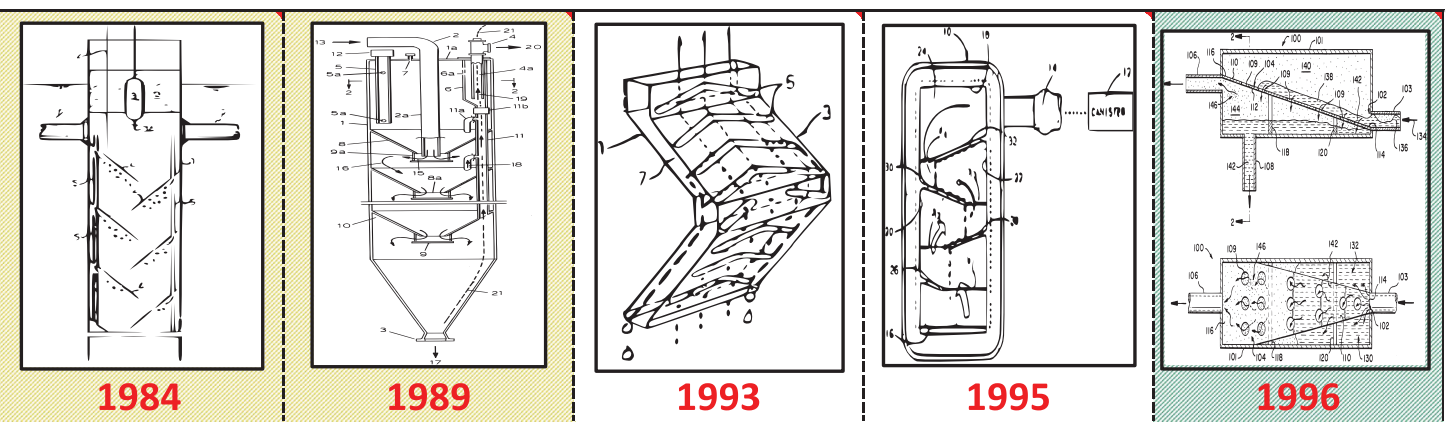

Figure 16. Excerpt from the timeline of patents that contain plate elements. 


\title{
Use of the Energetic Converters Database
}

\section{1- Select a Physical Effect}

\begin{tabular}{|c|c|c|}
\hline Energy (Input) & Converter/ Physical Effect & Energy (Output) \\
\hline Hydraulic & Bernoulli/Venturi Effect & Mechanical \\
\hline \multicolumn{2}{|l|}{ qvp } & VF \\
\hline \multicolumn{2}{|c|}{2 - Search in Patent Database } & $\begin{array}{l}\text { Espacenet } \\
\text { Patent search }\end{array}$ \\
\hline
\end{tabular}

GB 2401559 A

\begin{abstract}
A degasser comprising a main body having an inlet for a gas-liquid mixture which flows from the inlet under gravity over a weir 7 and into a reservoir 10 for degassed liquid, the level of which is controlled by a flotation device 11 and discrete outlets for the separated liquid 4 and gas 17 , the gas and liquid being |separated by pressure reduction occurring within the body and the gas loutlet being in the form of a vacuum, upreferably venturi, device 5 . A ball-valve|

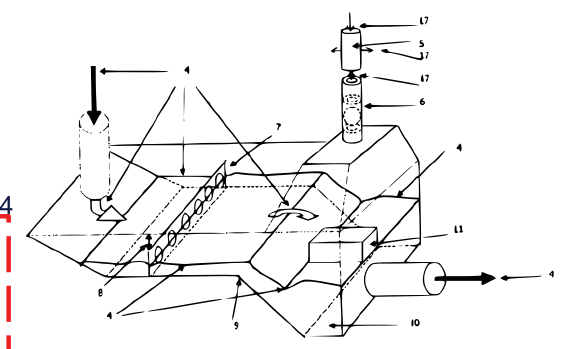

may be provided in the gas outlet to prevent unwanted discharge of liquid from the gas outlet and to prevent entry of gas into the body via the gas outlet. The floatation device may serve to close off the gas outlet in the event of there being an excess of liquid in the reservoir.
\end{abstract}

Figure 17. Example of the use of the converter database.

In this article, we do not address the construction of these trends, as this would require further explanations and several examples for a good understanding. A more detailed explanation, supported by several examples of our compilation of evolution trends, is the subject of a book chapter (Valverde, Nadeau, and Scaravetti, forthcoming).

(3) Application example of Axis 3: Changing the energetic converter

In the previous physical analysis of the cyclone (operator), the energy flow at the operator inlet was of hydraulic type, and mechanical-translation at the outlet (Figure 9). To change a fluid power (qv•p) into droplet displacement $(V \cdot F)$, we use the converter database. Several effects are available. As an example we will use the Venturi effect to increase the droplet transport velocity.

A new search is done with the keywords 'gas; liquid; separator; venturi', which produces no results. Through numerous previously performed iterations, the keyword 'degasser' is recovered (from the knowledge base of Figure 11). This keyword is often used in drilling language for biphasic separation. A new query is made with the keywords 'degasser; venturi'; 5 results are found. Patent GB2401559 separates the biphasic mixture by static pressure reduction, thus increasing velocity (Figure 17). 


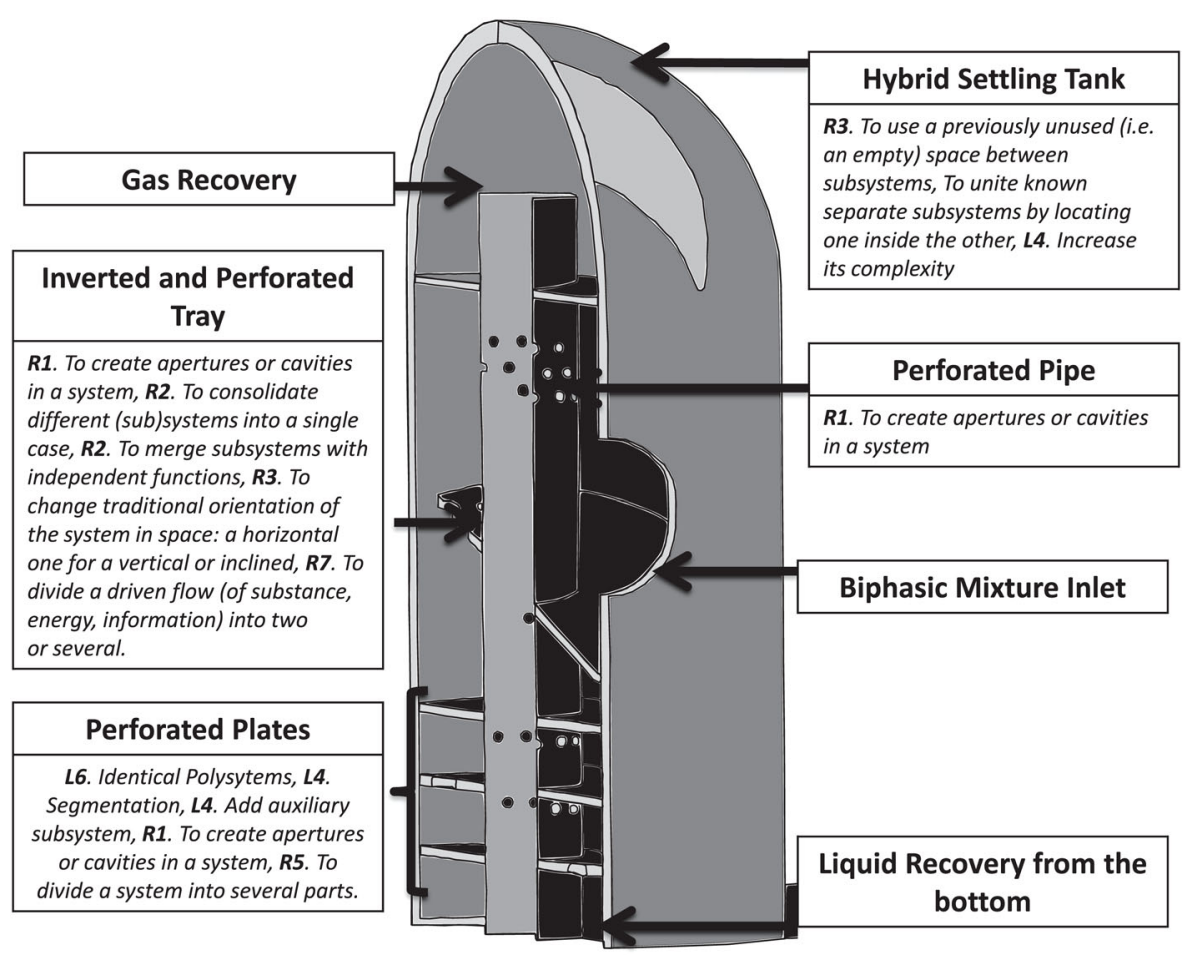

Figure 18. Biphasic separator: an incremental innovation. (R's - refers to the Polovinkin's Rules and L's refers to the Altshuller's Evolution Laws).

Exploring concepts using the converter database opens the door to new concepts in different research fields and shows its significance in the inspiration phase and in the search for other ideas.

\subsubsection{Innovative solutions: A hybrid solution}

Our hybrid concept is illustrated in Figure 18; it represents one of several possible conceptual solutions proposed to the oil industry. This hybrid concept is an alternative proposal to the use of a cyclone or a common settling tank (currently the most used).

Let us go over the essential concepts retrieved when analyzing by evolution trends. First, the incorporation of identical polysystems to increase the efficiency of an action (L6); next, trends towards segmenting one entity into several entities (L4), then incorporating different systems with identical functions (L6).

The constraints of working offshore generate a contradiction if we are using cyclones; our first proposal was based on the use of plates as this enables us to have large diameters. Another restriction imposed by the oil industry was the use of settling tanks as those currently installed. Therefore we should make a proposition based on an incremental innovation. The concept that was presented to the contractor involved a hybrid system, a gravity settling tank with plates, where fluid recovery is done from the bottom.

We start by taking relevant concepts found through patent analysis by evolution trends. Figure 18 shows a settling tank that incorporates horizontal perforated plates in order to 
refine the mixture separation; this concept was previously seen on Figure 16 (patent year 1993 addresses this problem). The mixture inlet is at the top, which means that it can then drop, thus promoting separation. The recovery of gas is done by means of a central tube; this solution is inspired by the lateral and internal recovery of Figure 15 (patent year 1998). Lastly, an inverted tray manages slug formation from the biphasic mixture due to the deceleration of the fluid; it also has perforations to promote biphasic separation before entering to the horizontal plates where mixture separation will continue. This concept was inspired by the 1996 patent (Figure 16) which will soon enter the public domain.

\section{Conclusion and discussion}

Patents do indeed constitute an important reservoir, richly endowed with exploitable technical information. A meticulous and structured exploration of the inventions will uncover essential knowledge for solving complex industrial problems. There is a broad range of methods and techniques that use the information available in patents, for several purposes such as economic, strategic, statistical, etc. Other approaches exploit patents to gather knowledge to support design activities. Many different approaches are more oriented towards the automation of complex tasks, such as analysis and knowledge extraction through computer science and artificial intelligence techniques. We can see a lack of finesse in the main function analysis phase of the problem in question, leading to an inadequate selection of initial keywords and consequently the recovery of a priori, irrelevant patents. Few of these methods implement a detailed physical analysis of the problem's main function, which is essential for a thorough understanding of the system in a problem-solving context.

The main contributions of our approach are first, a structured methodology divided into three stages which incorporates functional decomposition and a detailed physical analysis in order to improve the relevance of the initial keywords. A knowledge base is constructed by selecting pertinent keywords concatenated in a defined structure. This structure simplifies the generation of queries by using physical and technological keywords. A physical effects database contributes to the initial physical analysis and could be used to inspire users in their search for evolution opportunities. The discovery matrix enables users to classify the relevant patents and through the empty cells they can seek the first evolution opportunities. The analysis of patents in timeline through the evolution trends inspires users with some innovative solutions.

Our approach has limitations and potential improvement opportunities. All of the developed modules have an automatic part to facilitate the task, but the analysis of patents, the identification of pertinent keywords, and the functional decomposition must be done manually. Reading each document to extract pertinent information (such as physical phenomenon and technologies) during the analysis of patents, is a time-consuming task. Therefore, an improvement opportunity is the implementation of techniques, methods and tools from artificial intelligence, to reduce the analysis time. Future collaborative work with other experts is required to automate several tasks as we do not have a computing or semantic expertise. This methodology should also be applied in other industrial areas in order to corroborate its validity and reliability. 


\section{Disclosure statement}

No potential conflict of interest was reported by the authors.

\section{References}

Altshuller, Genrikh Saulovich. 1984a. Creativity as an Exact Science: The Theory of the Solution of Inventive Problems. Gordon and Breach Science Publishers. https://books.google.fr/books?id= ejJlllj5m-UC.

Altshuller, Genrikh Saulovich. 1984b. Creativity as an Exact Science: The Theory of the Solution of Inventive Problems. Gordon and Breach Science Publishers.

Altshuller, Genrich Saulovich. 1994. And Suddenly the Inventor Appeared TRIZ, the Theory of Inventive Problem Solving. Edited by Lev Shulyak. www.triz.org.

Anne, Kao, and R. Poteet Sthephen. 2009. Natural Language Processing and Text Mining. Edited by Springer. doi:10.1007/978-1-84628-754-1.

Bécue, Mathieu, Marina Flamand, and Vincent Frigant. 2013. “Une Analyse Des Trajectoires Inventives À Travers Le Triptyque Brevet, Réglementation , Finance: Le Cas de L'ophtalmologie Laser." Revue internationale d'intelligence économique 5: 51-70.

Bellis, Nicola De. 2009. Bibliometrics and Citation Analysis. Lanham, MD: The Scarecrow Press.

Calle-Escobar, Manuela, Ricardo Mejía-Gutiérrez, Jean-Pierre Nadeau, and Jérôme Pailhes. 2014. "Heuristics-based Design Process." International Journal on Interactive Design and Manufacturing (IJIDeM) 10: 369-386. doi:10.1007/s12008-014-0248-x.

Carvalho, Marco Aurélio de, Tz-chin Wei, and Semyon D Savransky. 2004. 121 Heuristics for Solving Problems. USA: Lulu Press.

Cascini, Gaetano, and Paolo Risonne. 2001. "Automatic Patents Functional Analysis through Semantic Processing." The 12th ADM international conference, Rimini, Italy.

Cavallucci, Denis, and Nikolai Khomenko. 2007. "From TRIZ to OTSM-TRIZ: Addressing Complexity Challenges in Inventive Design." International Journal of Productive Development 4 (1/2): 4-21. doi:10.1504/IJPD.2007.011530.

Cavallucci, Denis, François Rousselot, and Cécilia Zanni. 2011. “Using Patents to Populate an Inventive Design Ontology." Procedia Engineering 9: 52-62. doi:10.1016/j.proeng.2011.03.100.

Chang, Pao-Long, Chao-Chan Wu, and Hoang-Jyh Leu. 2012. "Investigation of Technological Trends in Flexible Display Fabrication through Patent Analysis." Displays 33 (2). Elsevier B.V.: 68-73. doi:10.1016/j.displa.2012.03.003.

Chen, Liang, Naoyuki Tokuda, and Hisahiro Adachi. 2003. "A Patent Document Retrieval System Addressing Both Semantic and Syntactic Properties." Proceedings of the ACL-2003 Workshop on Patent Corpus Processing 20: 1-6. doi:10.3115/1119303.1119304.

Cheong, H., I. Chiu, L. H. Shu, R. B. Stone, and D. A. Mcadams. 2011. "Biologically Meaningful Keywords for Functional Terms of the Functional Basis." Journal of Mechanical Design 133 (February): 1-11. doi:10.1115/1.4003249.

Cheong, Hyunmin, and L. H. Shu. 2014. "Retrieving Causally Related Functions from Natural-language Text for Biomimetic Design." Journal of Mechanical Design 136 (8): 081008. doi:10.1115/1.4027494.

Choi, Sungchul, Hyunseok Park, Dongwoo Kang, Jae Yeol Lee, and Kwangsoo Kim. 2012. "An SAObased Text Mining Approach to Building a Technology Tree for Technology Planning." Expert Systems with Applications 39 (13). Elsevier Ltd: 11443-11455. doi:10.1016/j.eswa.2012.04.014.

Chulvi, Vicente, and Rosario Vidal. 2011. "Usefulness of Evolution Lines in Eco-design." Procedia Engineering 9: 135-144. doi:10.1016/j.proeng.2011.03.107.

Costantini, Valeria, Francesco Crespi, and Ylenia Curci. 2015. "A Keyword Selection Method for Mapping Technological Knowledge in Specific Sectors through Patent Data: The Case of Biofuels Sector." Economics of Innovation and New Technology 24 (4).

El-Haik, Basem Said. 2005. AXIOMATIC QUALITY Integrating Axiomatic Design with Six-sigma, Reliability, and Quality Engineering. John Wiley \& Sons.

EPO. 2016. "European Patent Office." http://www.epo.org/searching-for-patents/technical/ espacenet.html\#tab1. 
Fantoni, G., R. Apreda, F. Dell'Orletta, and M. Monge. 2013. "Automatic Extraction of Function-behaviour-state Information from Patents." Advanced Engineering Informatics 27 (3): 317-334. doi:10.1016/j.aei.2013.04.004.

Fellbaum, Christiane. 1998. Wordnet: An Electronic Lexical Database. Cambridge, MA: MIT Press.

Fu, Katherine, James Dilmore, Jonathan Cagan, and Charles H. Dougherty Jr. 2013. "Using Design Database Structures to Characterize Freedom-to-Operate in a Design Space: A Legal Case Study." Proceedings of the 19th international conference on engineering design (ICED13), design for harmonies, Vol.1: design processes. Seoul, Korea.

Fu, Katherine, Joel Chan, Jonathan Cagan, Kenneth Kotovsky, Christian Schunn, and Kristin Wood. 2013. "The Meaning of"Near" and"Far': The Impact of Structuring Design Databases and the Effect of Distance of Analogy on Design Output." Journal of Mechanical Design 135 (February): 1-12. doi:10.1115/1.4023158.

Fu, Katherine, Jonathan Cagan, Kenneth Kotovsky, and Kristin Wood. 2013. "Discovering Structure in Design Databases through Functional and Surface Based Mapping." Journal of Mechanical Design 135 (March 2013): 31006. doi:10.1115/1.4023484.

Gero, John S. 1990. "Design Prototypes: A Knowledge Representation Schema for Design." Al Magazine 11 (4): 26. doi:10.1609/aimag.v11i4.854.

Gero, John S., and Udo Kannengiesser. 2004. "The Situated Function-behaviour-structure Framework." Design Studies 25 (4): 373-391. doi:10.1016/j.destud.2003.10.010.

Gomez, Guillermo Valente. 2010. “Enrichissement de Requêtes et Visualisation Sémantique Dans Une Coopération de Systèmes D'information: Méthodes et Outils D'aide À La Recherche D'information." Ph.D Thesis., Université de Bourgogne.

Ingwersen, Peter, and Kalervo Järvelin. 2005. The Turn Integration of Information Seeking and Retrieval in Context. Springer.

Jakus, Grega, Veljko Milutinović, Sanida Omerović, and Sašo Tomažič. 2013. Concepts, Ontologies, and Knowledge Representation. Springer. doi:10.1007/978-1-4614-7822-5.

Jeong, Yujin, and Byungun Yoon. 2015. "Development of Patent Roadmap Based on Technology Roadmap by Analyzing Patterns of Patent Development." Technovation 39-40 (May): 37-52. doi:10.1016/j.technovation.2014.03.001.

Lee, Sungjoo, Byungun Yoon, and Yongtae Park. 2009. "An Approach to Discovering New Technology Opportunities: Keyword-based Patent Map Approach." Technovation 29 (6-7): 481-497. doi:10.1016/j.technovation.2008.10.006.

Li, Miao, Xinguo Ming, Maokuan Zheng, Zhitao Xu, and Lina He. 2013. "A Framework of Product Innovative Design Process Based on TRIZ and Patent Circumvention." Journal of Engineering Design 24 (12): 830-848. doi:10.1080/09544828.2013.856388.

$\mathrm{Li}$, Yan-Ru, Leuo-Hong Wang, and Chao-Fu Hong. 2009. "Extracting the Significant-rare Keywords for Patent Analysis." Expert Systems with Applications 36 (3). Elsevier Ltd: 5200-5204. doi:10.1016/j.eswa.2008.06.131.

Li, Zhen, Derrick Tate, Christopher Lane, and Christopher Adams. 2012. "A Framework for Automatic TRIZ Level of Invention Estimation of Patents Using Natural Language Processing, Knowledgetransfer and Patent Citation Metrics." Computer-Aided Design 44 (10). Elsevier Ltd: 987-1010. doi:10.1016/j.cad.2011.12.006.

Loh, Han Tong, Cong He, and Shen Lixiang. 2006. "Automatic Classification of Patent Documents for TRIZ Users." World Patent Information 28 (1): 6-13. doi:10.1016/j.wpi.2005.07.007.

Melucci, Massimo, and Ricardo Baeza-Yates. 2011. Advanced Topics in Information Retrieval. Information Retrieval. Vol. 25. Springer. doi:10.1007/978-3-642-20946-8.

Nadeau, Jean-pierre, and Jérôme Pailhès. 2007. "L'analyse Des Phénomènes Physiques, Éléments Essentiels Vers La Résolution de Problèmes Industriels." Mechanique \& Industries 8: 165-171. doi:10.1051/meca:2007035.

Nadeau, Jean-pierre, and Jérôme Pailhès. 2010. Méthodologie En Conception Préliminaire. Arts et Métiers ParisTech.

Narin, Francis. 2000. "Tech-Line Background Paper." Imperial College Press Technology Management Series: "Measuring Strategic Competence" 1999 (August 1999). http://scholar.google.com/ scholar?hl $=$ en\&btnG $=$ Search\&q $=$ intitle:Tech-Line $+^{\circ}+$ BACKGROUND+PAPER\#0. 
Nickles, Thomas. 1981. "What Is a Problem That We May Solve It?" Scientific Method as a ProblemSolving and Question- Answering Technique 47 (1): 85-118. http://www.jstor.org/stable/20115620.

OuYang, Kuang, and Calvin S. Weng. 2011. "A New Comprehensive Patent Analysis Approach for New Product Design in Mechanical Engineering." Technological Forecasting and Social Change 78 (7). Elsevier Inc.: 1183-1199. doi:10.1016/j.techfore.2011.02.012.

Pahl, Gerhard, and Wolfgang Beitz. 1988. Engineering Design A Systematic Approach. Springer-Verlag. Pailhès, Jérôme, and Jean-Pierre Nadeau. 2007. "Innover En Conception Par Les Méthodes D'Aide À L'INnovation MAL'IN." 7ème congrès international de génie industriel, Troisrivières, Canada.

Pailhès, Jérôme, Mohammed Sallaou, Jean-Pierre Nadeau, and Georges M. Fadel. 2011. “Energy Based Functional Decomposition in Preliminary Design." Journal of Mechanical Design 133 (5): 051011. doi:10.1115/1.4004193.

Park, Hyunseok, Janghyeok Yoon, and Kwangsoo Kim. 2013. "Using Function-Based Patent Analysis to Identify Potential Application Areas of Technology for Technology Transfer." Expert Systems with Applications 40 (13). Elsevier Ltd: 5260-5265. doi:10.1016/j.eswa.2013.03.033.

Park, Hyunseok, Jason Jihoon Ree, and Kwangsoo Kim. 2013. "Identification of Promising Patents for Technology Transfers Using TRIZ Evolution Trends." Expert Systems with Applications 40 (2). Elsevier Ltd: 736-743. doi:10.1016/j.eswa.2012.08.008.

Park, Hyunseok, Kwangsoo Kim, Sungchul Choi, and Janghyeok Yoon. 201. "A Patent Intelligence System for Strategic Technology Planning." Expert Systems with Applications 40 (7). Elsevier Ltd: 2373-2390. doi:10.1016/j.eswa.2012.10.073.

Polovinkin, Alexander. 1991. "Theory of New Technique Design: Laws of Technical Systems and Their Application [In Russian]." Informelektro Moscow, 98-102.

Russo, Davide, and Tiziano Montecchi. 2011a. "Creativity Techniques for a Computer Aided Inventing System." ICED 11 - 18th international conference on engineering design - impacting society through engineering design, 362-373. Lyngby/Copenhagen, Denmark.

Russo, Davide, and Tiziano Montecchi. 2011b. "A Function-Behaviour Oriented Search for Patent Digging." Proceedings of the ASME 2011 international design engineering technical conferences \& computers and information in engineering conference, 1-10. doi:10.1115/DETC2011-47733.

Russo, Davide, Tiziano Montecchi, and Liu Ying. 2012. "Functional-Based Search for Patent Technology Transfer." ASME international design engineering technical conferences and computers and information in engineering conference, 1-11. doi:10.1115/DETC2012-70833.

Sallaou, Mohammed. 2008. "Taxonomie Des Connaissances et Exploitation En Conception Préliminaire - Application a Un Système Éolien -." Arts et Métiers ParisTech.

Samet, Wafa. 2010. "Développement D'une Méthode D'éco-Innovation: Eco-MAL'IN." Arts et Métiers ParisTech.

Savransky, Semyon D. 2000. Engineering of Creativity, Introduction to TRIZ Methodology of Inventive Problem Solving. CRC Press.

Setchi, Rossitza, and Carole Bouchard. 2010. "In Search of Design Inspiration: A Semanticbased Approach." Journal of Computing and Information Science in Engineering 10 (3): 145. doi:10.1115/1.3482061.

Souili, Achille, and Denis Cavallucci. 2012. "Toward an Automatic Extraction of IDM Concepts from Patents." CIRP Design 2012: 115-124. doi:10.1007/978-1-4471-4507-3.

Souili, Achille, Denis Cavallucci, and François Rousselot. 2015a. "Identifying and Reformulating Knowledge Items to Fit with the Inventive Design Method (IDM) Model for a Semantically-Based Patent Mining." In TRIZ FUTURE, TF 2011-2014, 131:1130-1139. Elsevier B.V. doi:10.1016/j.proeng.2015. 12.432.

Souili, Achille, Denis Cavallucci, and François Rousselot. 2015b. "Natural Language Processing (NLP) - A Solution for Knowledge Extraction from Patent Unstructured Data." In TRIZ FUTURE, TF 2011-2014, 131:635-643. Elsevier B.V. doi:10.1016/j.proeng.2015.12.457.

Souili, Achille, Denis Cavallucci, François Rousselot, and Cecilia Zanni. 2015. "Starting from Patents to Find Inputs to the Problem Graph Model of IDM-TRIZ." In TRIZ FUTURE, TF 2011-2014, 131:150-161. Elsevier B.V. doi:10.1016/j.proeng.2015.12.365.

Stalph, Patrick. 2014. Analysis and Design of Machine Learning Techniques. Springer. doi:10.1007/978-3658-04937-9. 
Suh, N P. 1990. The Principles of Design. Oxford Series on Advanced Manufacturing. Oxford University Press. https://books.google.fr/books?id = Z5fF5qQPQ9sC.

Tian, Liang, Yang Zhiping, and Hu Zhengyin. 2013. "The Large Aperture Optical Elements Patent Search System Based on Domain Knowledge Organization System." World Patent Information. Elsevier Ltd, 1-5. doi:10.1016/j.wpi.2013.04.007.

Tor, Bruun, Fiveland Torbjoern, and Werswick Bjoernar. 2012. "Gas-Liquid Separator." United State patent US2012/000643.

Tseng, Yuen-Hsien, Chi-Jen Lin, and Yu-I Lin. 2007. "Text Mining Techniques for Patent Analysis." Information Processing \& Management 43 (5): 1216-1247. doi:10.1016/j.ipm.2006.11.011.

Valverde, Ulises, Jean-Pierre Nadeau, and Dominique Scaravetti. Forthcoming. "Finding Innovative Technical Solutions in Patents Through Improved Evolution Trends." In TRIZ - The Theory of Inventive Problem Solving: Current Research and Trends in French Academic Institutions, edited by Denis Cavallucci, Chapter 1. Springer.

Valverde, Ulises, Jean Pierre Nadeau, Dominique Scaravetti, and Jean François Leon. 2014. "Innovation Through Pertinent Patents Research Based on Physical Phenomena Involved." 24th CIRP design conference 21. Milan, Italy, 515-520. doi:10.1016/j.procir.2014.02.061.

Verhaegen, P. A., J. D'hondt, J. Vertommen, S. Dewulf, and J. R. Duflou. 2009. “Relating Properties and Functions from Patents to TRIZ Trends." CIRP Journal of Manufacturing Science and Technology 1 (3): 126-130. doi:10.1016/j.cirpj.2008.09.010.

White, Michael. 2010. "Patent Searching: Back to the Future How to Use Patent Classification Search Tools to Create Better Searches." 1st CEEA conference: queen's university Kingston. Ontario. http://library.queensu.ca/ojs/index.php/PCEEA/issue/view/338.

Yoon, Byungun, and Yongtae Park. 2004. "A Text-mining-based Patent Network: Analytical Tool for High-technology Trend." The Journal of High Technology Management Research 15 (1): 37-50. doi:10.1016/j.hitech.2003.09.003.

Yoon, Janghyeok, and Kwangsoo Kim. 2011. "An Automated Method for Identifying TRIZ Evolution Trends from Patents." Expert Systems with Applications 38 (12). Elsevier Ltd: 15540-15548. doidoi:10.1016/j.eswa.2011.06.005.

Yoon, Janghyeok, and Kwangsoo Kim. 2012. "TrendPerceptor: A Property-Function Based Technology Intelligence System for Identifying Technology Trends from Patents." Expert Systems with Applications 39 (3). Elsevier Ltd: 2927-2938. doi:10.1016/j.eswa.2011.08.154.

Yukio, Ohsawa. 2003. Chance Discovery. Edited by McBurney Peter. doi:10.1007/978-3-662-06230-2.

Zouaoua-ragab, Dalia. 2012. "Lois D'évolution de TRIZ Pour La Conception Des Futures Générations Des Produits: Proposition D'un Modèle". 